Acta Crystallographica Section D

Biological Crystallography

ISSN 1399-0047
Navdeep S. Sidhu, ${ }^{\text {a,b }}$ Kathrin Schreiber, ${ }^{a}$ Kevin Pröpper, ${ }^{b} \neq$ Stefan Becker, ${ }^{\mathrm{c}}$ Isabel Usón, ${ }^{\mathrm{d}, \mathrm{e}}$ George M. Sheldrick, butta Gärtner, ${ }^{a}$ Ralph Krätzner ${ }^{\mathrm{a} *}$ and Robert Steinfeld ${ }^{\mathrm{a} *}$

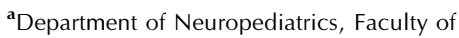
Medicine, University of Göttingen, RobertKoch-Strasse 40, 37075 Göttingen, Germany, ${ }^{\mathbf{b}}$ Department of Structural Chemistry, Institute of Inorganic Chemistry, University of Göttingen, Tammannstrasse 4, 37077 Göttingen, Germany, ${ }^{c}$ Max Planck Institute for Biophysical Chemistry, Am Fassberg 11, 37077 Göttingen, Germany d Instituto de Biologia Molecular de Barcelona (IBMB-CSIC), Barcelona Science Park, Baldiri Reixach 15, 08028 Barcelona, Spain, and e Institucio Catalana de Recerca i Estudis Avancats (ICREA), Spain

₹ Deceased 4 July 2013

Correspondence e-mail: rkraetz@gwdg.de, rsteinfeld@med.uni-goettingen.de

\title{
Structure of sulfamidase provides insight into the molecular pathology of mucopolysaccharidosis IIIA
}

Mucopolysaccharidosis type IIIA (Sanfilippo A syndrome), a fatal childhood-onset neurodegenerative disease with mild facial, visceral and skeletal abnormalities, is caused by an inherited deficiency of the enzyme N-sulfoglucosamine sulfohydrolase (SGSH; sulfamidase). More than 100 mutations in the SGSH gene have been found to reduce or eliminate its enzymatic activity. However, the molecular understanding of the effect of these mutations has been confined by a lack of structural data for this enzyme. Here, the crystal structure of glycosylated SGSH is presented at $2 \AA$ resolution. Despite the low sequence identity between this unique $\mathrm{N}$-sulfatase and the group of $\mathrm{O}$-sulfatases, they share a similar overall fold and active-site architecture, including a catalytic formylglycine, a divalent metal-binding site and a sulfate-binding site. However, a highly conserved lysine in $\mathrm{O}$ sulfatases is replaced in SGSH by an arginine (Arg282) that is positioned to bind the $\mathrm{N}$-linked sulfate substrate. The structure also provides insight into the diverse effects of pathogenic mutations on SGSH function in mucopolysaccharidosis type IIIA and convincing evidence for the molecular consequences of many missense mutations. Further, the molecular characterization of SGSH mutations will lay the groundwork for the development of structure-based drug design for this devastating neurodegenerative disorder.

\section{Introduction}

Mucopolysaccharidoses (MPS) are a group of recessively inherited lysosomal storage disorders caused by a deficiency of enzymes involved in the metabolic breakdown of glycosaminoglycans (GAGs; also known as mucopolysaccharides). GAGs are unbranched polysaccharide chains consisting of repeating disaccharide units that contain variable modifications. In the cases of heparin and heparan sulfate, the degree of $\mathrm{O}$ - and $\mathrm{N}$ sulfation is crucial for the biological function of these GAGs (Turnbull et al., 2010).

At least 11 different enzyme deficiencies are currently known to be associated with the lysosomal storage of glycoaminoglycans (Ballabio \& Gieselmann, 2009). The inherited MPS disorders show multiple clinical symptoms such as facial dysmorphism, skeletal dysplasia, hepatosplenomegaly and variable signs of neurodegeneration (Clarke, 2008). In the subtypes III of mucopolysaccharidoses, also called Sanfilippo syndrome, signs of neurodegeneration are the initial symptoms and comprise of hyperactivity, developmental stagnation and psychomotor regression (Valstar et al., 2010). Mucopolysaccharidosis type IIIA (MPS IIIA) is caused by the functional defect of N-sulfoglucosamine sulfohydrolase (SGSH; also known as sulfamidase, sulfamate sulfohydrolase and heparan N-sulfatase; EC 3.10.1.1) and represents one of the most
Received 5 November 2013

Accepted 5 February 2014

PDB references: sulfamidase, $4 \mathrm{mhx} ; 4 \mathrm{miv}$ 
frequent lysosomal storage diseases worldwide. Its incidence ranges from 0.68 per 100000 to 1.21 per 100000 in European countries (Héron et al., 2011; Baehner et al., 2005).

SGSH belongs to the sulfatase family and catalyses the cleavage of N-linked sulfate groups from the GAGs heparan sulfate and heparin. The active site is characterized by the amino-acid sequence motif $\mathrm{C}(X)$ PSR that is highly conserved among most sulfatases from all species. The leading cysteine is post-translationally converted to a formylglycine (FGly) residue, which is crucial for the catalytic process (Dierks et al., 1999, 2005; Daniele \& Di Natale, 2001).

Currently, there is no effective therapy available for MPS IIIA. Pathophysiological changes in the brain are the major determinants of the clinical picture. However, intravenous enzyme-replacement therapy is hampered by the very limited ability of the enzyme to cross the blood-brain barrier. While the structures of many O-sulfatases have been determined (Boltes et al., 2001; Bond et al., 1997; Hernandez-Guzman et al., 2003; Lukatela et al., 1998; Rivera-Colón et al., 2012; van Loo et al., 2010), no structures are available for an $\mathrm{N}$-sulfatase such as SGSH. In addition, since SGSH shares only a very low sequence identity (approximately 19-25\%) with O-sulfatases with known structures, understanding the molecular basis of this lethal disease is incomplete (Perkins et al., 1999).

To understand the catalytic mechanism of human SGSH at the molecular level and to gain insight into the functional consequences of clinically relevant SGSH mutations, we determined its crystal structure in two crystal forms to resolutions of 2.00 and $2.40 \AA$. We compare the structure of SGSH as an enzyme cleaving $\mathrm{N}$-linked sulfate groups with its closest $\mathrm{O}$-sulfatase homologues that hydrolyze O-linked sulfates and discuss the structural consequences of clinically known mutations. Our results reveal structural deviations of SGSH from O-sulfatases and disclose unique features of its substratebinding site.

\section{Materials and methods}

\subsection{Protein expression and purification}

The amino-acid sequence RSHHHHHH was introduced at the C-terminus of the SGSH protein to facilitate purification. Transfection of the modified SGSH cDNA and selection of HEK 293 cells were performed as described previously (Steinfeld et al., 2004). Recombinant protein samples of SGSH were purified from the cell-culture supernatant. The medium was cleared by centrifugation at $3000 \mathrm{~g}$ and $4^{\circ} \mathrm{C}$ for $60 \mathrm{~min}$ and was then filtered with a $0.2 \mu \mathrm{m}$ pore membrane. After adding $20 \mathrm{mM} \mathrm{K} \mathrm{K}_{2} \mathrm{HPO}_{4} \mathrm{pH} 7.5,0.5 \mathrm{M} \mathrm{NaCl}, 40 \mathrm{~m} M$ imidazole, the crude solution was loaded onto a HisTrap HP column (GE Healthcare, Freiburg, Germany). Bound SGSH was eluted at an imidazole concentration of $250 \mathrm{~m} M$ with a step gradient. For crystallization, the purified SGSH fractions were pooled and concentrated using a centrifugal filter (Millipore, Schwalbach, Germany). The final protein solution contained $10 \mathrm{mg} \mathrm{ml}^{-1}$ SGSH and was adapted to $10 \mathrm{~m} M$ Tris $\mathrm{pH} 7.5$, $100 \mathrm{~m} M \mathrm{NaCl}$. Enzyme purity was checked using SDS-PAGE.

\subsection{Protein crystallization}

We obtained two different crystal forms of SGSH: a smallcell (S) form and a large-cell (L) form. Both forms were obtained using the sitting-drop vapour-diffusion method at $293 \mathrm{~K}$. The $\mathrm{S}$ form was obtained in robotic crystallization screening trials set up in 96-well Greiner plates using Tecan Genesis RSP 150 and TTP Labtech Mosquito robots. The reservoir and drop volumes were 100 and $0.1 \mu \mathrm{l}$, respectively. The drop was prepared by mixing the protein solution with the reservoir solution in a 1:1 ratio. Rod-shaped crystals of maximum dimensions $20 \times 20 \times 50 \mu \mathrm{m}$ grew over several weeks in $25 \%(w / v)$ polyethylene glycol (PEG) $3350,200 \mathrm{mM}$ $\mathrm{MgCl}_{2}, 100 \mathrm{~m} M$ HEPES buffer $\mathrm{pH}$ 7.5. The $\mathrm{L}$ form was obtained during manual optimization trials, with rod-shaped crystals of typical dimensions $50 \times 50 \times 350 \mu \mathrm{m}$, in $13 \%(w / v)$ PEG 8000, $200 \mathrm{mM} \mathrm{MgCl}_{2}, 100 \mathrm{~m} M$ bis-tris buffer $\mathrm{pH}$ 5.1.

\subsection{Data collection}

Native single-crystal X-ray diffraction data were collected on the PXII beamline at the Swiss Light Source using monochromatic radiation of wavelength $0.99989 \AA$ A with a Pilatus 6M detector, an oscillation range of $0.1^{\circ}$ and an exposure time of $0.1 \mathrm{~s}$. A total of 3600 images were collected for the S crystal form, for which the space group was determined to be $P 2_{1}$, with unit-cell parameters $a=61.4, b=107.9, c=79.8 \AA$, $\beta=104.1^{\circ} ; 1800$ images were collected for the L crystal form, which also crystallized in space group $P 2_{1}$, with an approximately four times larger unit cell: $a=103.0, b=211.6$, $c=108.4 \AA, \beta=102.7^{\circ}$. Data reduction was performed using the programs XDS (Kabsch, 2010) and XPREP (Sheldrick, 2012). Resolution limits for the small and large cells were set at 2.00 and $2.40 \AA$, respectively, based on self-correlation coefficients (Karplus \& Diederichs, 2012) of approximately $65 \%$ for each. Table 1 lists the data-collection and refinement statistics.

\subsection{Structure solution and refinement}

The crystal structure of Pseudomonas aeruginosa sulfatase (Boltes et al., 2001; PDB entry 1hdh), which shares a structurebased sequence identity of approximately $22 \%$ with SGSH, was used as the basis from which to derive search-model fragments for molecular replacement (MR) in the small cell, as implemented in the program ARCIMBOLDO (Rodríguez et al., 2009), and to combine the outcome to design an optimal MR search model. An initial rotation-translation solution with two incomplete monomers in the asymmetric unit was found that was clearly discriminated by MR figures of merit from all other solutions. However, attempts to refine this solution as such failed. Systematic attempts were made to improve the solution by disassembling parts of the model based on structure-based sequence alignments with close homologues, rigid-body refinement of rigid groups in Phaser (McCoy et al., 2007) as part of the CCP4 suite of programs (Winn et al., 2011), and low-resolution rigid-body and jellybody refinement in REFMAC (Winn et al., 2011; Murshudov et al., 1997, 2011), gradually increasing the resolution. The 
Table 1

Data-collection and refinement statistics.

The number of atoms is the occupancy sum; $B$ factors are occupancy-weighted means. Solvent atoms were excluded when calculating the mean $B$ factors for individual chains.

\begin{tabular}{|c|c|c|}
\hline Crystal form & S & $\mathrm{L}$ \\
\hline PDB code & $4 \mathrm{mhx}$ & $4 \mathrm{miv}$ \\
\hline Space group & $P 2_{1}$ & $P 2_{1}$ \\
\hline \multicolumn{3}{|l|}{ Unit-cell parameters } \\
\hline$a(\AA)$ & 61.4 & 103.0 \\
\hline$b(\AA)$ & 107.9 & 211.6 \\
\hline$c(\AA)$ & 79.8 & 108.4 \\
\hline$\beta\left({ }^{\circ}\right)$ & 104.1 & 102.7 \\
\hline \multicolumn{3}{|l|}{ Data collection } \\
\hline Wavelength $(\AA)$ & 0.99989 & 0.99989 \\
\hline Resolution range $\dagger(\AA)$ & $\begin{array}{l}44.3-2.00 \\
\quad(2.10-2.00)\end{array}$ & $\begin{array}{l}48.9-2.40 \\
\quad(2.50-2.40)\end{array}$ \\
\hline No. of reflections measured & 452472 & 599199 \\
\hline No. of unique reflections & 67940 & 174779 \\
\hline Multiplicity $\dagger$ & $6.65(6.38)$ & $3.41(3.45)$ \\
\hline$R_{\text {merge }} \dagger$ & $0.0886(0.6539)$ & $0.0702(0.4723)$ \\
\hline$R_{\sigma}^{\dagger}$ & $0.0500(0.5504)$ & $0.0594(0.4917)$ \\
\hline Completeness $\dagger(\%)$ & $99.9(99.8)$ & $99.3(98.7)$ \\
\hline Mean $I / \sigma(I) \dagger$ & $11.20(1.85)$ & $11.03(2.08)$ \\
\hline \multicolumn{3}{|l|}{ Refinement } \\
\hline Resolution limit $(\AA)$ & $44.3-2.00$ & $48.85-2.40$ \\
\hline$R_{\text {free }}$ (No. of reflections) & $0.2299(3447)$ & $0.2447(8462)$ \\
\hline$R_{\mathrm{work}}$ & 0.1920 & 0.2157 \\
\hline Total No. of reflections (working set) & 64437 & 166273 \\
\hline Solvent content $(\%)$ & 45.9 & 53.0 \\
\hline No. of molecules in the asymmetric unit & 2 & 8 \\
\hline No. of non-H atoms refined & 7968 & 31122 \\
\hline \multirow{2}{*}{\multicolumn{3}{|c|}{ Mean $B$ factors $\left(\AA^{2}\right)$}} \\
\hline & & \\
\hline Protein atoms & 44.7 & 64.5 \\
\hline Backbone atoms & 43.5 & 64.2 \\
\hline Side-chain atoms & 45.9 & 64.8 \\
\hline Water atoms & 39.0 & 37.6 \\
\hline Chain $A$ & 45.5 & 48.9 \\
\hline Chain $B$ & 43.9 & 44.1 \\
\hline Chain $C$ & - & 48.3 \\
\hline Chain $D$ & - & 44.9 \\
\hline Chain $E$ & - & 85.5 \\
\hline Chain $F$ & - & 75.8 \\
\hline Chain $G$ & - & 79.6 \\
\hline Chain $H$ & - & 93.0 \\
\hline \multicolumn{3}{|l|}{ R.m.s.d.s from ideal geometry } \\
\hline Bond lengths $(\AA)$ & 0.0125 & 0.0028 \\
\hline Bond angles $\left({ }^{\circ}\right)$ & 1.564 & 0.683 \\
\hline \multicolumn{3}{|l|}{ Ramachandran statistics } \\
\hline Favored region (\%) & $97.1(933 / 961)$ & $97.2(3727 / 3835)$ \\
\hline Allowed region (\%) & $99.8(959 / 961)$ & $99.7(3823 / 3835)$ \\
\hline Outlier region $(\%)$ & $0.21(2 / 961)$ & $0.31(12 / 3835)$ \\
\hline
\end{tabular}

$\dagger$ Values in parentheses are for the outermost resolution shell.

program SCWRL4 (Krivov et al., 2009) was initially used to model and test secondary-structure-based side-chain rotamers. The criteria monitored included the log-likelihood gain and the fit of the model to the electron density. A significantly incomplete but refinable model was finally obtained. For the $R_{\text {free }}$ set for cross-validation of the structure models, $5 \%$ of all reflections were put aside randomly for the small cell; SFTOOLS (Winn et al., 2011), MTZ2HKL (Grune, 2008) and $X P R E P$ were used to place aside, in 21 thin shells (2.45$48.9 \AA), 8462(4.8 \%)$ of all reflections for the large cell.

A partial structural model for the $\mathrm{S}$ crystal form was then used as a search model to solve the structure of the $\mathrm{L}$ form using Phaser. This latter cell contained eight molecules in the asymmetric unit. Density modification with NCS averaging over the small-cell and large-cell crystal forms could now be used with the program DMMULTI as part of CCP4 (Winn et al., 2011; Cowtan, 1994), facilitating structure building in the $S$ form. Manual building could subsequently be complemented by piecemeal corrections derived from automatic chain tracing using the program Buccaneer as part of CCP4 (Winn et al., 2011; Cowtan, 2006). A completed model was then used to re-solve and refine the large-cell structure. Model building was peformed using Coot (Emsley et al., 2010). Maximumlikelihood refinement of model coordinates against the working set data was performed using REFMAC5.5 with local NCS restraints. Water molecules were added automatically or manually in Coot. Waters were deleted manually if the refined density was weak, if the $B$ factor refined to values exceeding $80 \AA^{2}$ or if the waters were too close to neighbouring atoms or too distant from the protein. In the final refinement macrocycles, $\mathrm{H}$ atoms were added in riding positions and TLS parameters were refined (Murshudov et al., 2011). The final $R_{\text {free }}$ (Brünger, 1992) and $R_{\text {work }}$ are 22.99 and $19.20 \%$, respectively, for the small cell and 24.47 and $21.57 \%$, respectively, for the large cell. SGSH monomer superposition r.m.s.d.s were calculated using Indonesia (Madsen et al., 2005); those for the dimer were calculated using $L S Q K A B$ (Kabsch, 1976). Figures were drawn using PyMOL (Mura et al., 2010) or an in-house program (NSS, unpublished work). Accessible surface area was calculated using the PISA server (Krissinel \& Henrick, 2007). Normalized accessible surface area (NASA) per atom per residue was calculated by setting the accessible surface area per atom per residue for Lys490 as 100 and expressing the values for other residues in relation to this as a percentage. A model of the substrate was docked using the program AutoDock Vina (Trott \& Olson, 2010).

\subsection{SGSH activity assay}

SGSH activities were determined by a fluorometric assay as described previously (Karpova et al., 1996). The enzymatic activity of SGSH was measured in a two-step reaction: 4methylumbelliferyl- $\alpha$-D- $N$-sulfoglucosaminide (MU- $\alpha$ GlcNS) is desulfated by SGSH to become a substrate for $\alpha$-glucosidase, which converts 4-methylumbelliferyl- $\alpha$-D- $N$ sulfoglucosamine (MU- $\alpha \mathrm{Glc})$ to methylumbelliferone (MU), which is a fluorescent compound. The amount of MU can be quantified at wavelengths of $360 \mathrm{~nm}$ (excitation) and $460 \mathrm{~nm}$ (emission) using an external MU standard curve. Briefly, SGSH from a stock solution $\left(0.8 \mathrm{mg} \mathrm{ml}^{-1}\right)$ was diluted 1:100 with water containing $\mathrm{NaCl}(0.9 \%)$ and $\mathrm{BSA}(0.2 \%) .10 \mu \mathrm{l}$ of this SGSH solution was gently mixed with $20 \mu$ l substrate buffer (14.3 $\mathrm{m} M$ sodium barbital, $14.3 \mathrm{~m} M$ sodium acetate $\mathrm{pH}$ $6.5,0.7 \% \mathrm{NaCl}, 2.28 \mathrm{mg} \mathrm{ml}^{-1} \mathrm{MU}-\alpha \mathrm{GlcN}$ ) and $10 \mu \mathrm{l}$ inhibitor solution, which was prepared using $\mathrm{KH}_{2} \mathrm{PO}_{4}$ or $\mathrm{Na}_{2} \mathrm{SO}_{4}$ in water to reach final concentrations of 500, 250, 100, 50, 10, 5, 2.5, 1 or $0.5 \mathrm{mM} \mathrm{SO}_{4}^{2-}$ or $\mathrm{PO}_{4}^{3-}$ in the mixture. As a control for full enzymatic activity, $10 \mu \mathrm{l}$ pure water was added instead of the inhibitor solution. The reaction mixture was incubated for 
$2 \mathrm{~h}$ in a 96-well plate at $37^{\circ} \mathrm{C}$ and shaken at $300 \mathrm{rev} \mathrm{min}{ }^{-1}$. Subsequently, $6 \mu \mathrm{l} \mathrm{P}_{\mathrm{i}} / \mathrm{Ci}$ buffer $(0.4 M$ sodium phosphate, $0.2 M$ citrate $\mathrm{pH} 6.7)$ and $10 \mu \mathrm{l} \alpha$-glucosidase $\left(10 \mathrm{U} \mathrm{ml}^{-1}\right.$, $0.2 \%$ BSA) were added. After incubation for $24 \mathrm{~h}$ at $37^{\circ} \mathrm{C}$, $150 \mu \mathrm{l}$ stop buffer $\left(0.175 \mathrm{M}\right.$ glycine $\left./ \mathrm{Na}_{2} \mathrm{CO}_{3}\right)$ was added, followed by fluorometric measurement of enzymatic activity. in all ten chains in the two crystal forms, but lies in good density.

\subsection{Structure of the SGSH monomer}

The crystal structure of glycosylated human SGSH was solved using molecular replacement. The monomeric enzyme

\section{Results}

Full-length human SGSH was expressed in HEK 293 cells and was purified from the cell-culture supernatant. A tworesidue $\mathrm{C}$-terminal linker followed by a six-His tag (residues 503-510) was used to assist in purification of the recombinantly produced enzyme.

Two crystal forms of glycosylated SGSH were grown at different $\mathrm{pH}$ values. The crystal form grown at $\mathrm{pH} 7.5$ is designated crystal form $\mathrm{S}$ (small unit cell). The structure of this form was refined to $2.00 \AA$ resolution. The form grown at $\mathrm{pH} 5.1$ is designated crystal form $\mathrm{L}$ (large unit cell). Its structure was refined to $2.40 \AA$ resolution. There are two molecules in the asymmetric unit of crystal form $\mathrm{S}$ and eight molecules in that of form L. The enzyme appears to exist as a homodimer in both crystal forms.

\subsection{Model quality}

For crystal form S, continuous electron density of good quality was observed for both molecules in the asymmetric unit; residues 22-504 were modelled in chain $A$ and residues 22 503 in chain $B$. For crystal form L, the quality of the electron density varied significantly for the eight molecules in the asymmetric unit, with better density for approximately half of the molecules (chains $A-D$ ); the number of modelled residues ranged from 485 (residues 21-505) in chain $A$ to 481 (residues 22502 with residues $185-186$ unmodelled) in chain $F$. Since the protein $\varphi / \psi$ angles were not restrained during refinement, they serve as an indicator of model quality. The Ramachandran plot (Lovell et al., 2003; Ramakrishnan \& Ramachandran, 1965) values and data-collection and refinement statistics are listed in Table 1. Asp94 is an outlier
22

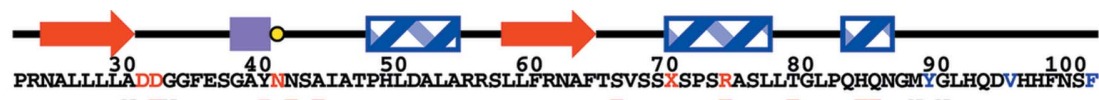

102

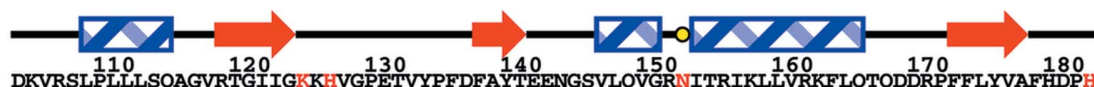

182
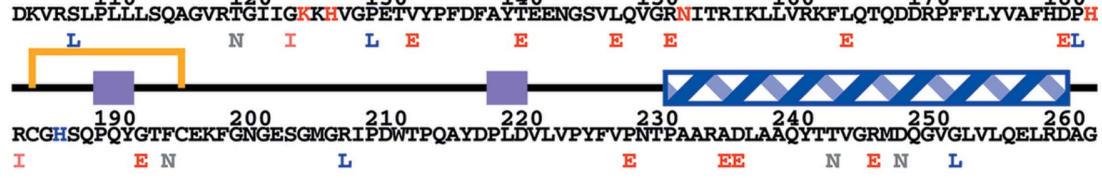

262

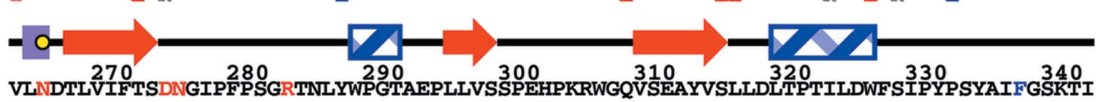

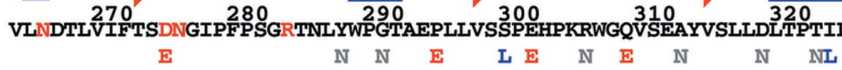

342
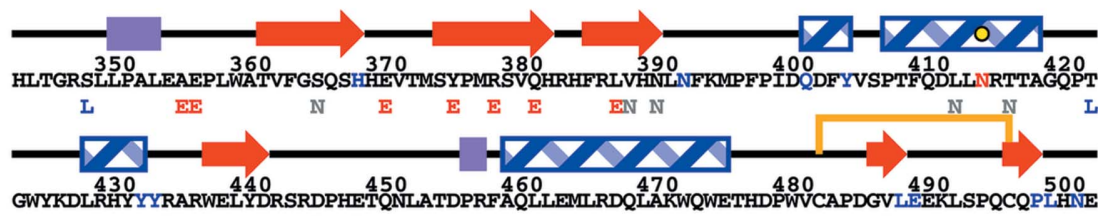
L $\quad E$

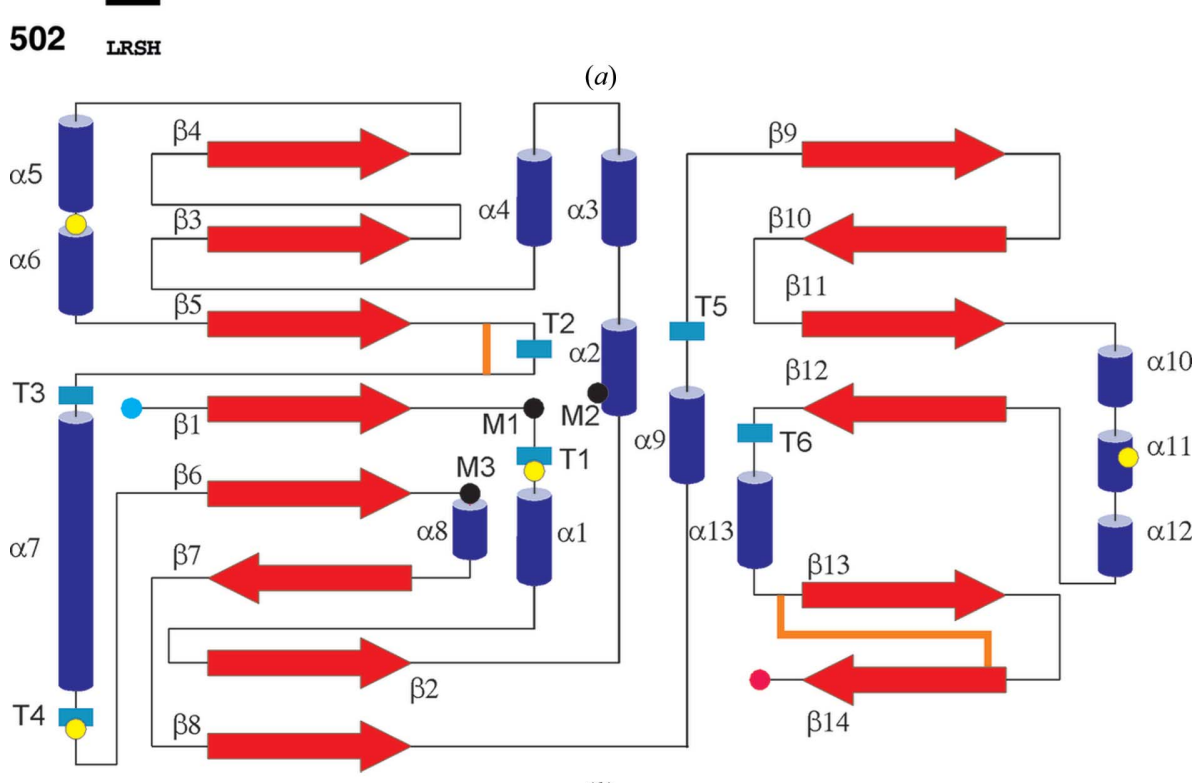

(b)

Figure 1

Schematic representations of the SGSH structure. (a) Mapping of SGSH primary and secondary structures. $\beta$-Strands, red arrows; $\alpha$-helices, blue striped rectangles; $33_{10}$-helices, violet rectangles; the two disulfide bridges are shown as orange lines and the four glycosylated asparagines as yellow filled circles. Functionally important residues (active site and glycosylation sites) are shown in red; some of the residues at the dimer interface are shown in blue. The phenotype of the missense mutation sites is indicated below the sequence as follows: early-onset disease (E), red; intermediate-onset (I), orange; late-onset (L), blue; phenotype not reported in the literature $(\mathrm{N})$, grey. $(b)$ Topology diagram (not drawn to scale). Colour coding is similar to that in Fig. 1(a), with $\alpha$-helices shown as blue cylinders and the $\mathrm{N}$-terminus and $\mathrm{C}$-terminus as blue and red circles, respectively. Divalent metal-binding residues are labelled M1 (Asp31, Asp32), M2 (FGly70) and M3 (Asp273, Asn274). Secondary-structure elements are named as indicated in the main text. 
subunit comprises of two domains, each centred on a $\beta$-sheet: a large $\mathrm{N}$-terminal domain (domain 1 ) and a smaller C-terminal domain (domain 2), as is typical for the sulfatase fold. There are $14 \beta$-strands, $13 \alpha$-helices and six $3_{10}$-helices (T1T6) in total [Fig. 1; classification based on Kabsch \& Sander (1983) as implemented in PROCHECK (Winn et al., 2011)]. Domain 1 has an $\alpha / \beta$ form. Its core is formed by a mixed $\beta$-sheet consisting of eight $\beta$-strands, all except one of which are parallel, with nine decorating $\alpha$-helices on both sides of the $\beta$-sheet (Fig. 1b). One of the helices is 30 residues in length (helix $\alpha 7$ ). The core of domain 2 is formed by a four-stranded antiparallel $\beta$-sheet, with four surrounding $\alpha$-helices, followed by a C-terminal extension consisting of a small two-stranded antiparallel $\beta$-sheet. The enzyme contains two intrasubunit

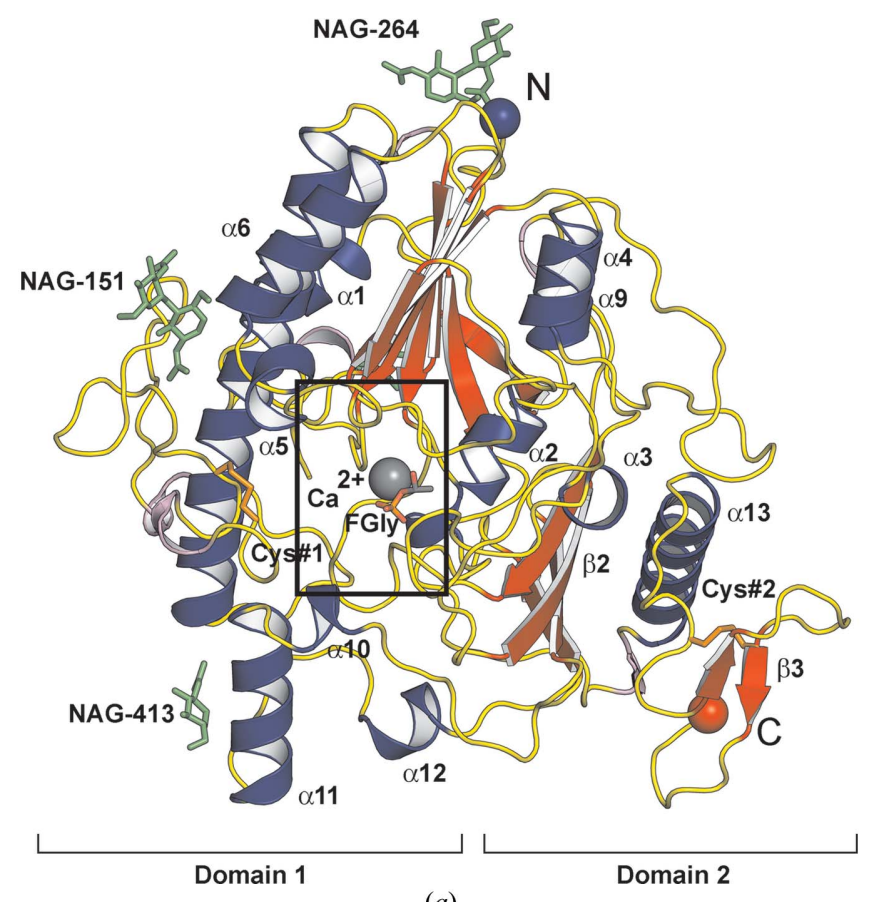

(a)
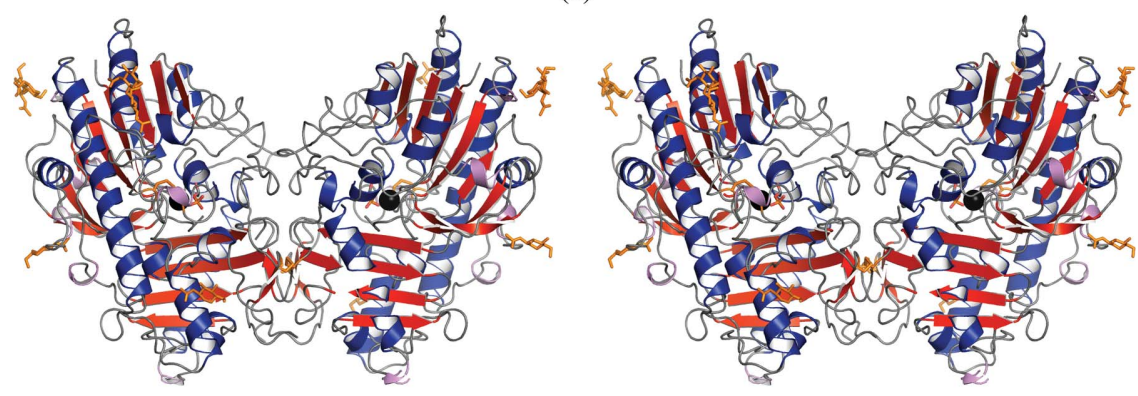

(b)

Figure 2

Three-dimensional structure of SGSH. (a) Monomer. The approximate locations of domains 1 and 2 are shown (square brackets), with $\beta$-sheets in domain 2 labelled $\beta 2$ and $\beta 3$. $\beta$-Strands are shown in red, $\alpha$-helices in blue and loops in yellow. Cystine bridges are shown in orange (Cys\#1, 183-194; Cys\#2, 481-495). The N-terminus (N) is shown as a blue ball and the C-terminus (C) as an orange ball. The formylglycine (FGly) 70 side chain is shown as a stick model in standard colours. The $\mathrm{Ca}^{2+}$ ion is shown as a grey ball. Glycosylation sites ('NAG-' followed by the asparagine residue number) are shown as green sticks. (b) Dimer. The dimer noncrystallographic symmetry axis lies vertically in the plane of the paper, with subunit centroids in the approximate paper plane on either side of it. FGly70, cystine bridges and glycosylations are shown as orange stick models. Other representations are as in Figs. 1 and $2(a)$. disulfide bonds. One of these (Cys183-Cys194) stabilizes a long, loop-rich segment ( $\beta 5-\alpha 7$; residues $177-229)$ in domain 1. The second (Cys481-Cys495) ties the C-terminal extension to a proximal loop in domain 2 (Fig. 2a). Electron density corresponding to glycosylated residues was observed at Asn41, Asn151, Asn264 and Asn413, in agreement with four of the five glycosylation sites previously reported (Di Natale $e t$ al., 2001); no glycosylation could be detected at Asn142. There are four cis-peptide bonds in both chains, between prolines and the preceding Gly127, Asp179, Ala482 and Ser492; all of em lie in good density. , homodimer (Fig. 2b), burying approximately $10.3 \%$ of the accessible surface area of each subunit.

\subsection{SGSH shows low structural flexibility}

Since the SGSH structure was determined in two crystal forms, $\mathrm{S}$ and $\mathrm{L}$, we could use the ten crystallographically independent monomers of SGSH to assess the structural flexibility of the enzyme under two different crystallization conditions. The enzyme subunits display a low rigid-body structural flexibility in the $\mathrm{S}$ form $\left(\mathrm{C}^{\alpha}\right.$ r.m.s.d. of $0.20 \AA$ between the two chains, with NCS restraints) as well as the $\mathrm{L}$ form (r.m.s.d. ranging from 0.10 to $0.17 \AA$, with NCS restraints). To investigate the mobility at the dimer interface, all five homodimers were superimposed based on one of the subunits in each dimer. The relative orientation of the dimer subunits in the $\mathrm{L}$ form differs from that in the $\mathrm{S}$ form by $2.6-3.0^{\circ}$, indicating that the dimer interface is slightly flexible, possibly owing to crystal packing.

\subsection{The active site and inhibition of SGSH by sulfate and phosphate}

The consensus active site lies in domain 1 in a narrow pocket at the bottom of a surface cleft (Fig. 2c) and close to the end of the first $\beta$-strand. Electron density consistent with the position of a divalent metal ion in O-sulfatases was interpreted as $\mathrm{Ca}^{2+}$ based on bond-valence calculations (Müller et al., 2003). The metal ion is coordinated in a distorted, approximately octahedral arrangement by $\mathrm{O}$ atoms from the side chains of residues Asp31, Asp32, Asp273 and Asn274 and the phosphorylated FGly70, as shown in Fig. 2(d). A schematic overview of interactions in the active site is given in Fig. 3(a).

Since a clear differentiation between phosphate and sulfate as the species bound to FGly70 was not feasible based only on 
the electron density, we made quantitative measurements of the inhibitory effects of phosphate and sulfate on SGSH (Fig. $3 b)$. The $\mathrm{IC}_{50}$ values determined for phosphate and sulfate were 1 and $5 \mathrm{~m} M$, respectively, indicating preferential phosphate binding. Since $20 \mathrm{mM} \mathrm{K}_{2} \mathrm{HPO}_{4}$ was present in the purification buffer, the electron density joined to FGly70 was modelled as a phosphate group. This crucial catalytic residue is stabilized by multiple interactions. The bridging $\mathrm{O}$ atom between $\mathrm{C}^{\beta}$ of FGly70 and the phosphate moiety coordinates $\mathrm{Ca}^{2+}$, while the hydroxyl $\mathrm{O}$ atom interacts with the side chains of Arg74, Lys123 and His125. The phosphate is further stabilized by interactions between its distal $\mathrm{O}$ atoms and $\mathrm{Ca}^{2+}$, and the side chains of Lys123, His181 and Arg282.

\subsection{Homology of SGSH with O-sulfatases}

A Protein Data Bank (PDB) database search revealed only low sequence identities with known structures of O-sulfatases,

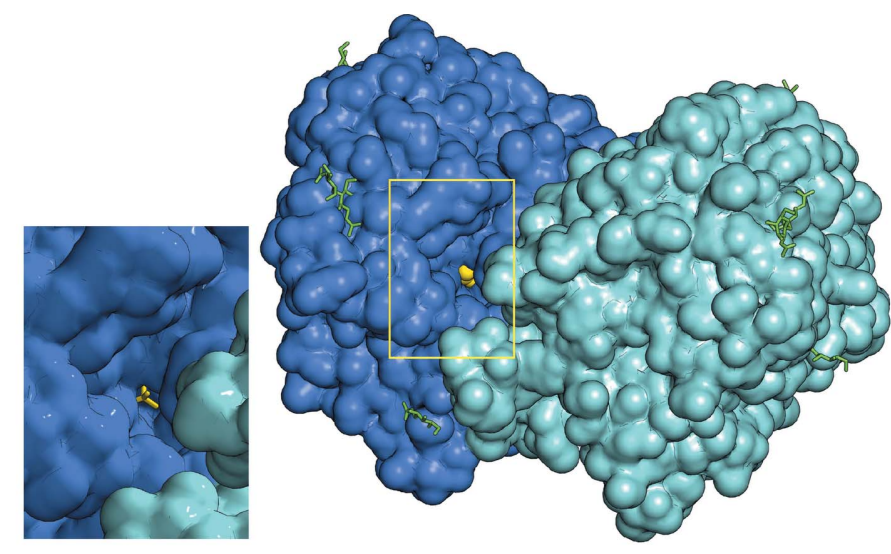

(c)
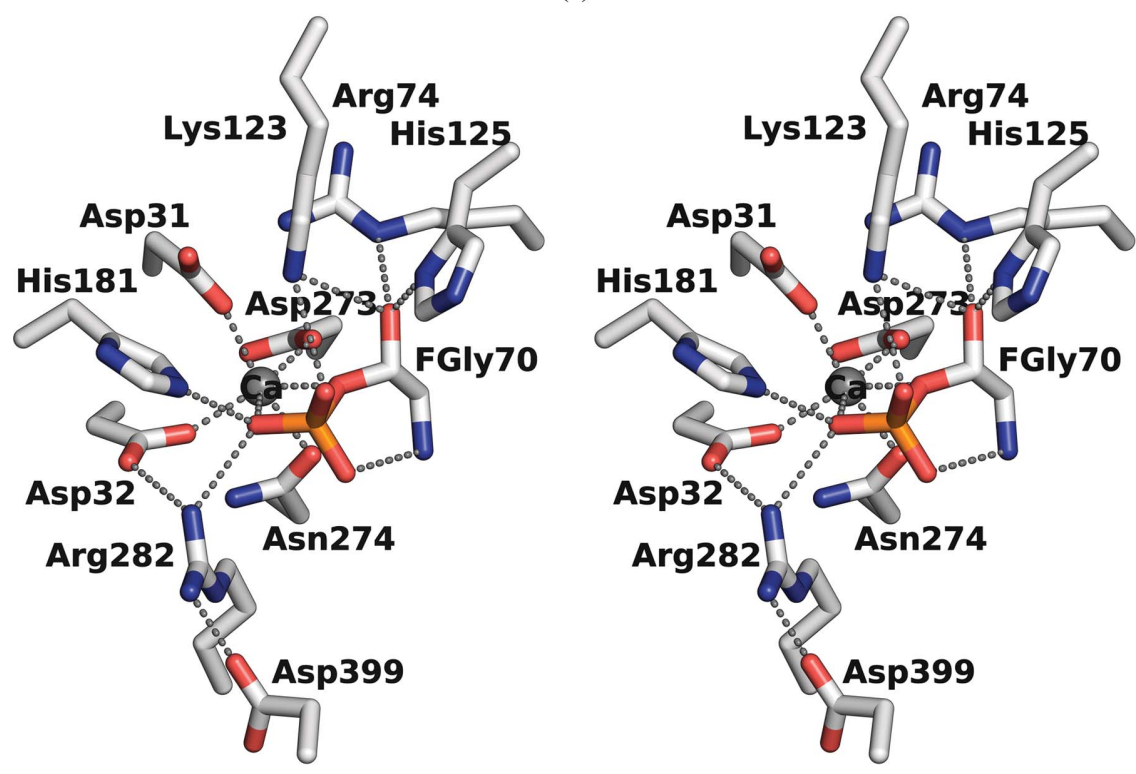

(d)

Figure 2 (continued)

(c) A short tunnel from a surface cleft leads to the active site. The inset on the left shows an enlargement of the boxed area. The two dimer subunits are shown in blue and cyan, FGly is shown as yellow spheres or sticks and glycosylations are shown as green sticks. $(d)$ Active site as viewed from its entry (stick models; the major interactions shown are described in the main text). ranging between 19 and $25 \%$ (Table 2). Five of these Osulfatases catalyze the hydrolysis of an $\mathrm{S}-\mathrm{O}$ bond in sulfate esters; the sixth is a phosphonate monoester hydrolase from Burkholderia caryophylli PG2952 (BcPMH) which acts on a broader range of substrates, including phosphate monoesters, diesters and triesters, phosphonate monoesters, sulfate monoesters and sulfonate monoesters (van Loo et al., 2010). Fig. 4 shows an overlay of the SGSH main chain (red) with five of these closest O-sulfatase homologues. The SGSH structure shares with other $\mathrm{N}$ - and $\mathrm{O}$-sulfatases the conserved fold of a large central $\beta$-sheet decorated by $\alpha$-helices on both sides. Structural differences are smallest in this area, while the loops protruding from this region, and the C-terminal domain, display a significant variability among these sulfatases. The active site lies at the boundary of the two regions. The entry to the active site traverses the unconserved region, presumably reflecting the structural differences between the different substrates of these enzymes. Although the catalytic centres of these sulfatases show a high degree of conservation; there are a few exceptions (Table 2), including the replacement of Arg282 in SGSH by a lysine in the Osulfatase homologues.

\section{Discussion}

In the current study, we describe the first structure of sulfamidase, deficient activity of which causes the disease Sanfilippo A syndrome (also known as mucopolysaccharidosis IIIA). To our knowledge, it is also the first reported structure of a sulfatase that breaks an $\mathrm{S}-\mathrm{N}$ sulfamate bond rather than an $\mathrm{S}-\mathrm{O}$ sulfate-ester bond. The overall structure of the $\mathrm{N}$-sulfatase SGSH subunit displays a characteristic sulfatase fold that is a member of the $\alpha / \beta$-hydrolase fold family (Nardini \& Dijkstra, 1999). The enzyme forms a homodimer in both of the two crystal forms for which structures were solved, with a calculated molecular weight of the mature unglycosylated subunit of $55 \mathrm{kDa}$. A comparison of all ten independent subunits in two different crystal forms of SGSH revealed low structural flexibility within the subunit. However, the dimer interface is slightly flexible, displaying a rotation of up to $3.0^{\circ}$ in the two crystal forms.

\subsection{Active site}

Residues neighbouring FGly70 in the active site are generally highly conserved between the $\mathrm{N}$-sulfatase SGSH and the closest $\mathrm{O}$-sulfatase homologues for which structures are available, excluding BcPMH. 
Notable exceptions are Arg282 (SGSH; discussed below), which is replaced by a lysine in these O-sulfatases, and the $\mathrm{Ca}^{2+}$-binding residue Asn274, which is replaced by a glutamine in ES. All ten important active-site residues in SGSH are conserved in the closest homologous sequences from diverse vertebrates and invertebrates that are tentatively annotated as SGSHs (Supplementary Fig. 1).

\section{Table 2}

Structurally equivalent active-site residues classified by (putative) function in SGSH and closely homologous sulfatases with known atomic structures.

ASA, arylsulfatase A (also known as human lysosomal cerebroside-3-sulfate 3-sulfohydrolase; Lukatela et al., 1998); ASB, arylsulfatase B (human lysosomal N-acetylgalactosamine-4-sulfate 4-sulfohydrolase (Bond et al., 1997); PAS, arylsulfatase from P. aeruginosa (Boltes et al., 2001); ES, human oestrone/dehydroepiandrosterone sulfatase (Hernandez-Guzman et al., 2003); GALNS, human lysosomal ( $N$-acetyl)galactosamine-6-sulfatase (Rivera-Colón et al., 2012); BcPMH, sulfatase/hydrolase from B. caryophylli PG2952 (van Loo et al., 2010). Sequence identities were calculated for protein sequences using the PROMALS3D server (Pei et al., 2008) and ClustalW2 (BcPMH; Goujon et al., 2010). R.m.s.d.s were calculated using Coot. Lys123 (SGSH numbering) and its equivalent residues in homologues also participate in sulfate binding.

\begin{tabular}{|c|c|c|c|c|c|c|c|}
\hline Enzyme & SGSH & PAS & ASA & ASB & GALNS & ES & $\mathrm{BcPMH}$ \\
\hline PDB code & $4 \mathrm{mhx}$ & $1 \mathrm{hdh}$ & 1auk & $1 \mathrm{fsu}$ & $4 \mathrm{fdi}$ & $1 \mathrm{p} 49$ & $2 w 8 s$ \\
\hline Sequence identity (\%) & 100 & 22.4 & 22.2 & 19.7 & 22.8 & 19.1 & 24.6 \\
\hline R.m.s.d. (§) (No. of residues) & $0.00(482)$ & $2.17(341)$ & $2.21(331)$ & $2.18(312)$ & $1.97(336)$ & $1.95(303)$ & $1.98(345)$ \\
\hline Desulfation & FGly70 & FGly51 & FGly69 & FGly91 & FGly79 & FGly75 & FGly57 \\
\hline Metal & $\mathrm{Ca}^{2+}$ & $\mathrm{Ca}^{2+}$ & $\mathrm{Mg}^{2+}\left(\mathrm{Ca}^{2+}\right) \dagger$ & $\mathrm{Ca}^{2+}$ & $\mathrm{Ca}^{2+}$ & $\mathrm{Ca}^{2+}$ & $\mathrm{Fe}$ \\
\hline \multirow[t]{4}{*}{ Metal binding } & Asp31 & Asp13 & Asp29 & Asp53 & Asp39 & Asp35 & Asp12 \\
\hline & Asp32 & Asp14 & Asp30 & Asp54 & Asp40 & Asp36 & - \\
\hline & Asp273 & Asp317 & Asp281 & Asp300 & Asp288 & Asp342 & Asp324 \\
\hline & Asn274 & Asn318 & Asn282 & Asn301 & Asn289 & Gln343 & His 325 \\
\hline \multirow[t]{3}{*}{ FGly binding } & Arg74 & Arg55 & Arg73 & Arg95 & Arg83 & Arg79 & Arg61 \\
\hline & Lys123 & Lys113 & Lys123 & Lys145 & Lys140 & Lys134 & Tyr105 \\
\hline & His 125 & His115 & His 125 & His147 & His142 & His136 & Thr107 \\
\hline \multirow[t]{2}{*}{ Sulfate binding } & His181 & His 211 & His 229 & His 242 & His 236 & His 290 & His 218 \\
\hline & $\operatorname{Arg} 282$ & Lys375 & Lys302 & Lys318 & Lys310 & Lys368 & Lys337 \\
\hline
\end{tabular}

$\dagger$ The identity of the divalent cation was later demonstrated to be $\mathrm{Ca}^{2+}$ in ASA structures with PDB codes $1 \mathrm{n} 2 \mathrm{k}$ and $1 \mathrm{n} 2 \mathrm{l}$ (Chruszcz et al., 2003).
An in silico prediction was made that histidines are not in the active site of sulfamidase from Flavobacterium um, thus distinguishing it from the active site of (Myette et al., 2009). In human SGSH, both O-sulfatases. However, a high degree of structural variabit between SGSH and O-sulfatases begins in the immediate neighbourhood of the active-site residues, specifically in the short tunnel leading to the active site and its surrounding surface cleft. This presumably enables SGSH and $\mathrm{O}$-sulfatases to accommodate distinct substrates that undergo a similar enzymatic reaction.

The crystallization conditions contained $\mathrm{Mg}^{2+}$ rather than $\mathrm{Ca}^{2+}$ ions. The latter ion is assumed to have bound to the enzyme intracellularly during expression and is the typical divalent cation for sulfatases (Table 2 and references therein). However, we are unable to exclude the possibility that at least some $\mathrm{Mg}^{2+}$ is also present in the metal-binding site.

\subsection{Enzymatic reaction mechanism}

SGSH catalyzes the cleavage of the $\mathrm{S}-\mathrm{N}$ bond in $\mathrm{N}$-sulfoglucosamine, desulfating the glycos-

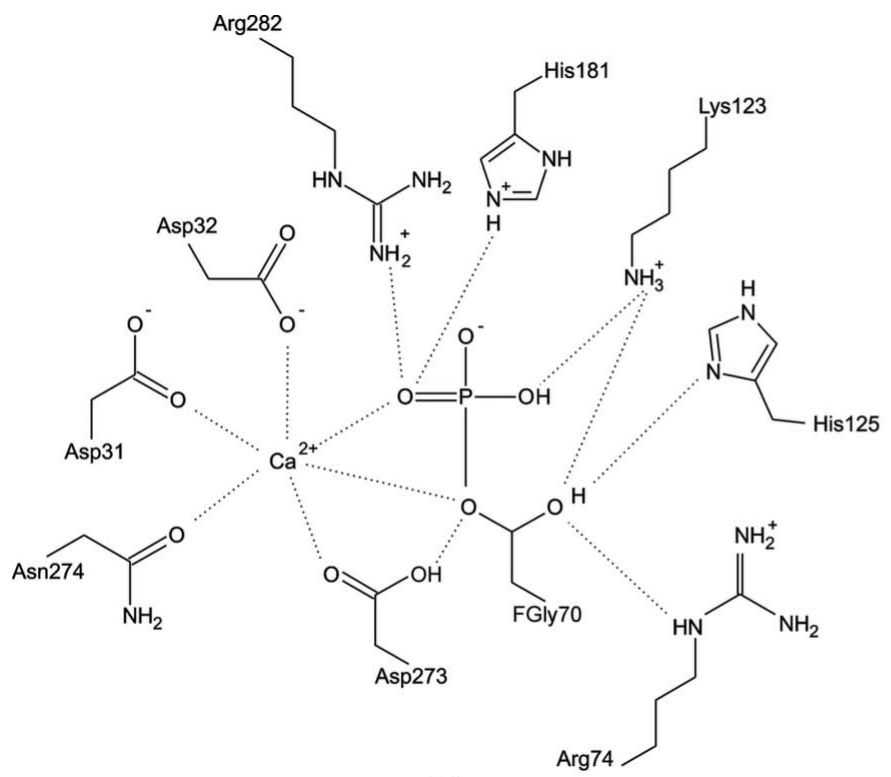

(a)

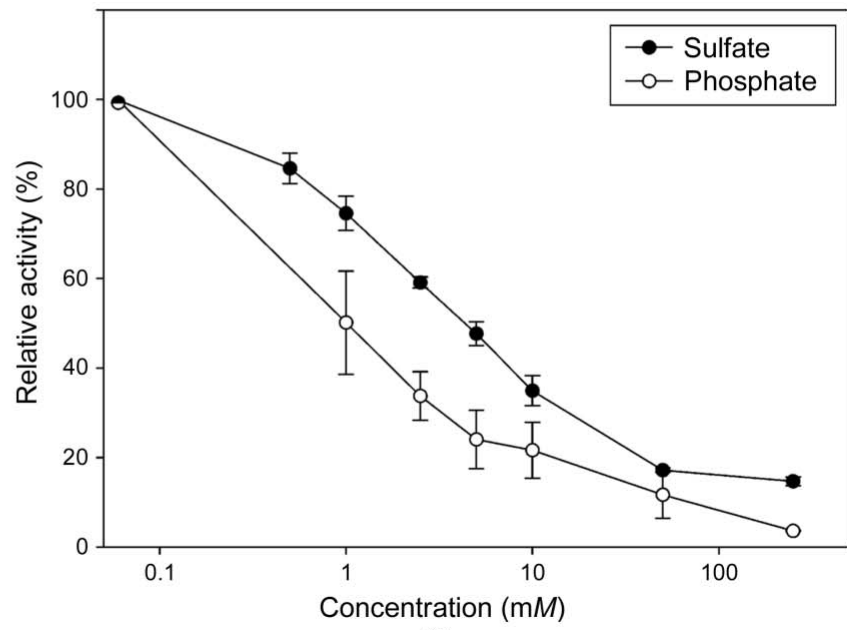

(b)

Figure 3

Active site and enzyme inhibition. (a) Schematic of the active-site region in SGSH. A Ca ${ }^{2+}$ ion is coordinated by side-chain P atoms from Asp31, Asp32, Asp273, Asn274 and the phosphorylated FGly70, which is in turn stabilized by interactions with the side chains of residues Arg74, Lys123, His125, His181, Asp273 and Arg282. (b) Inhibition of SGSH acitivity by phosphate and sulfate. The $\mathrm{IC}_{50}$ of phosphate was determined to be $1 \mathrm{mM}$; the $\mathrm{IC}_{50}$ of sulfate was $5 \mathrm{~m} M$. 
aminoglycan substrates heparan sulfate and heparin at the nonreducing terminus of the linear GAG chain. In analogy with the enzymatic reaction mechanism previously proposed for O-sulfatases (Boltes et al., 2001; von Bülow et al., 2001), we suggest that the substrate is first desulfated while sulfating the enzyme, which is then desulfated in turn (Fig. 5). Specifically, an activated $\mathrm{O}$ atom, $\mathrm{O}^{\gamma 2}$, from the hydrated form of formylglycine attacks the sulfur centre of the $\mathrm{N}$-linked sulfate group of the substrate, resulting in a covalently bound enzyme-substrate complex with a pentavalent sulfur in the transition state. In this step, the activation of the hydroxyl $\mathrm{O}$ atom involves transfer of its proton to a base, with a potential candidate being Asp273. An acidic group then facilitates the breakage of the $\mathrm{S}-\mathrm{N}$ bond by protonating the $\mathrm{N}$ atom to form an amine leaving group. The $\mathrm{N}$-desulfated substrate diffuses away, leaving an O-sulfated enzyme. Finally, a base (possibly His125) deprotonates the second $\mathrm{C}^{\beta}$ hydroxyl group of formylglycine, resulting in the formation of a double bond between the $\mathrm{O}$ atom and the $\mathrm{C}^{\beta}$ atom. While the bridging $\mathrm{C}^{\beta}-$ $\mathrm{O}$ bond to the sulfate group breaks, the sulfate ion is eliminated and the formylglycine residue is regenerated. The enzyme is now ready for another round of catalysis.

The identity of the acid that facilitates the breakup of the transition state with concomitant desulfation of the substrate is uncertain, with candidates suggested for PAS including Lys375, His211, the second hydroxyl group of FGly via the sulfate, or a water molecule. The species that act as the acid could plausibly change as a function of solution $\mathrm{pH}$ (Boltes et al., 2001). The role of His 211 as the acid has also been

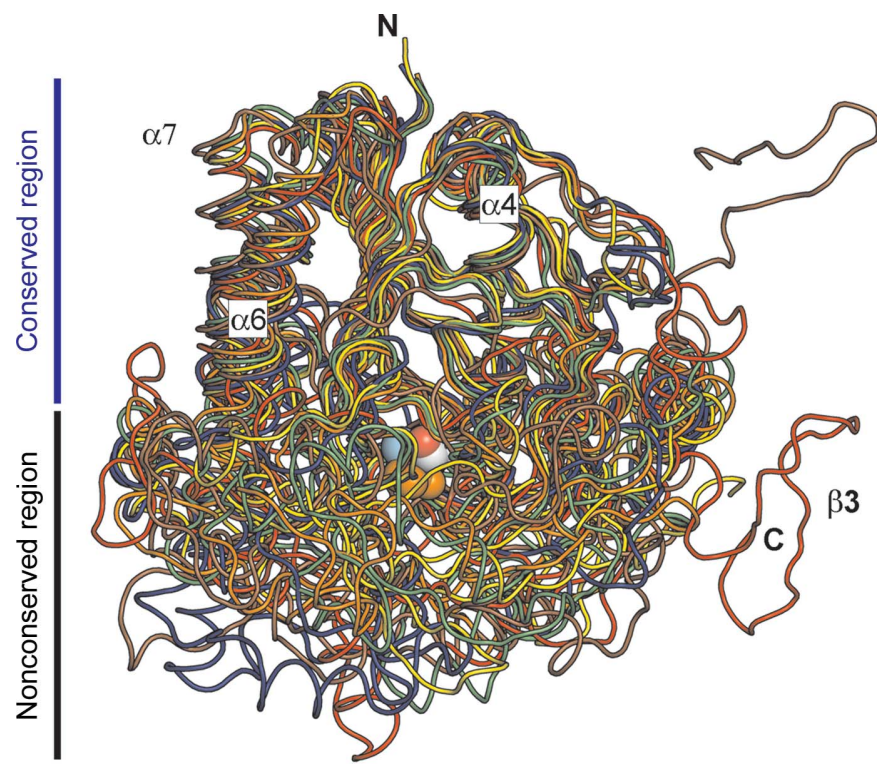

Figure 4

Superposition of the SGSH backbone on those of five related sulfatases: SGSH (red), ASA (orange), ASB (yellow), PAS (blue), GALNS (green) and BcPMH (brown). SGSH shares a common fold with O-sulfatases consisting of a large central $\beta$-sheet with decorating helices ('conserved region', top); the loops form a more variable region ('nonconserved region', bottom). For orientation, the SGSH N-terminus and C-terminus are shown ( $\mathrm{N}$ and $\mathrm{C}$, respectively), as are some secondary-structure elements (as in Fig. $2 a$ ) and some atoms in the active site in ball representation: $\mathrm{Ca}^{2+}$ (dark grey), phosphate $\mathrm{O}$ atoms (orange), FGly $\mathrm{C}^{\beta}$ (light grey) and free hydroxyl $\mathrm{O}$ atom (red). suggested by a recent density functional theory-based quantum-mechanical study based on the PAS structure (PDB entry $1 \mathrm{hdh}$; Marino et al., 2013). The residue corresponding to His211 is conserved in the other sulfatases, including SGSH (His181; Table 2). In order to identify plausible interactions in the active site, we generated an in silico docking model of nonphosphorylated SGSH derived from the present study with the substrate monosaccharide 2- $N$-sulfoglucosamine (Fig. 6). In this model, His181 is located close to the $\mathrm{N}$ atom of the leaving amine, at the site of the cleaved $\mathrm{S}-\mathrm{N}$ bond. His181 would be expected to be protonated at the lysosomal $\mathrm{pH}$ and thus appears to be a good potential candidate proton donor in the catalytic mechanism of SGSH.

The lysine equivalent to Lys375 in PAS is structurally conserved in all of these O-sulfatases, including BcPMH. However, in SGSH the lysine is replaced by an arginine (Arg282; SGSH numbering). The side chain of Arg282 forms salt bridges in the active site with Asp32 and Asp399, which are located $7.6 \AA$ apart on opposite sides of this arginine (Fig. $2 d$ ). An arginine at this position appears to be conserved in many putative sulfamidase sequences closely homologous to SGSH (Supplementary Fig. $1^{\mathbf{1}}$ ). Furthermore, arginine has been shown to interact up to 2.5 times more strongly with heparin than does lysine (Stenlund et al., 2002; Fromm et al., 1995). In the docking model mentioned above, the side chain of $\operatorname{Arg} 282$ lies close to one of the sulfate $\mathrm{O}$ atoms and the 3-hydroxyl $\mathrm{O}$ atom of the substrate, apparently orienting the substrate for catalysis. Taken together, these structural data suggest an important binding role for Arg282 in SGSH. The functional and structural effects resulting from the substitution of arginine by lysine will be investigated using an Arg282Lys SGSH mutant in the future.

Since our structural data cannot completely describe the reaction partners involved, we are unable to exclude an alternative reaction mechanism in which one of the sulfate $\mathrm{O}$ atoms attacks the $\mathrm{C}^{\beta}$ atom (Bond et al., 1997).

\subsection{Enzyme inhibition}

Phosphate buffer was used in the purification of SGSH. Difference density next to FGly70 in the active site could be modelled as a covalently bound phosphoryl group. However, based on our data we are unable to exclude that this is a covalently bound sulfate group. Sulfate and phosphate have both been found to inhibit arylsulfatase A from rabbit liver (Lee \& Van Etten, 1975) and human $N$-acetylgalactosamine6-sulfatase (Bielicki et al., 1995). Sulfate has previously been shown to be a strong inhibitor of SGSH (Freeman \& Hopwood, 1986). We found phosphate to be a more potent inhibitor of SGSH than sulfate, which supports the building of a phosphorylated FGly70 in the present structure.

\subsection{Molecular basis of disease-causing mutations}

The correlation of genotype with phenotype has often been difficult in MPS IIIA, with attendant difficulties in diagnosis

\footnotetext{
${ }^{\mathbf{1}}$ Supporting information has been deposited in the IUCr electronic archive (Reference: CB5050).
} 
and prognosis (Di Natale et al., 1998; Yogalingam \& Hopwood, 2001). Suggested explanations include genetic heterogeneity and difficulty in phenotypic classification, especially in a disease in which mental and behavioural symptoms typically dominate the clinical picture. Genetic, epigenetic and environmental modulating factors might further contribute to the phenotypic variability in MPS IIIA (Beesley et al., 2000; Di Natale et al., 1998; Perkins et al., 1999). Except for two relatively small regions of high-homology sulfatase consensussequence regions (residues 70-80 and 115-124), SGSH in general shares only a low sequence identity with $\mathrm{O}$-sulfatases for which atomic structures have been described. As a result, understanding the molecular basis of the disease has been especially difficult for this enzyme.

In Table 3, we list 80 disease-causing missense mutations that have been described in SGSH and briefly describe the predicted structural effects of these mutations based on the atomic structure of the enzyme determined in the present study. Fig. 7 displays these mutations as mapped onto the three-dimensional structure of the SGSH monomer. Most missense mutations for which disease severity has been reported in MPS IIIA patients are associated with a rapidly progressing, early-onset form of the disease (Di Natale et al., 2003). Approximately a quarter of the mutations affect surface residues. In the case of two mutations that affect buried residues but are associated with a late-onset phenotype, namely E292K and S298P, it appears plausible that the presence of buried waters in the wild-type genotype acts as an ameliorating factor by offering substitution space for the mutated side chain.

Three of the mutations (D32G, D32E and D273N) affect buried $\mathrm{Ca}^{2+}$-binding residues. While D32G and D273N lead to
1

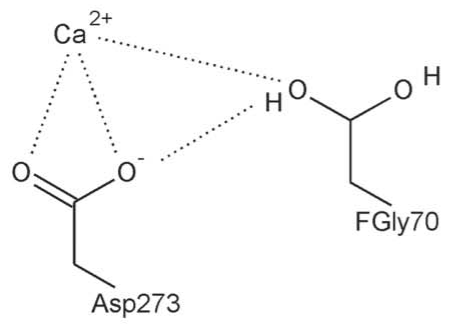

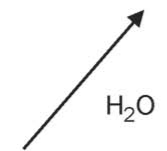

FGly70<smiles>O=S(=O)([O-])[O-]</smiles>

5

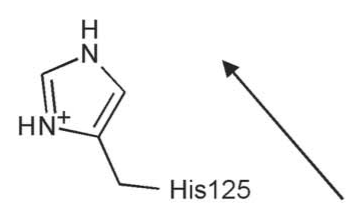<smiles>[R]NS(=O)(=O)O</smiles><smiles></smiles>
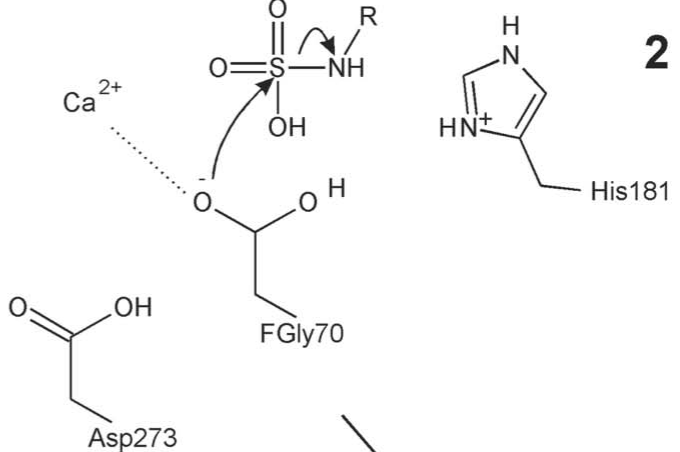

Fly70
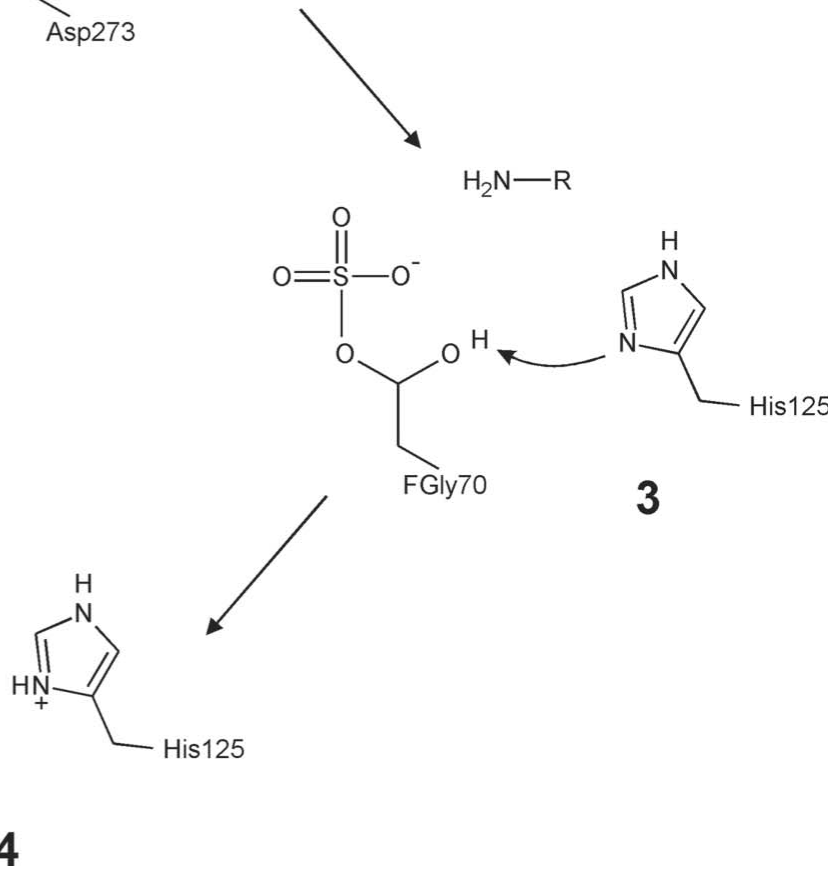

Figure 5

Proposed reaction mechanism in SGSH (schematic). The active-site formylglycine (FGly70), which is intrinsically reactive, undergoes hydration to form the resting state of the enzyme with a gem-diol group (step 1). Coordination of one of the hydroxyl groups of the gem-diol to a $\mathrm{Ca}^{2+}$ ion facilitates the development of a negative charge on the $\mathrm{O}$ atom as its proton is lost to a base. The negatively charged $\mathrm{O}$ atom nucleophilically attacks the sulfur centre of the N-linked sulfate group on the glucosamine substrate (step 2), resulting in a covalently bound enzyme-substrate complex with a pentavalent sulfur transition state. An acid (possibly His181) facilitates the cleavage of the $\mathrm{S}-\mathrm{N}$ bond by protonating the bridging $\mathrm{N}$ atom to form an amine leaving group on the N-desulfated substrate, which diffuses away, leaving an O-sulfated enzyme (step 3). Finally, in a step that underlines the importance of the formylglycine residue, another base (His125) deprotonates the second hydroxyl group, resulting in a negatively charged $\mathrm{O}$ atom (step 4) that forms a double bond with the $\mathrm{C}^{\beta}$ atom as the $\mathrm{C}-\mathrm{O}$ bond between it and the bridging $\mathrm{O}$ atom of the sulfate group breaks, eliminating the sulfate ion and regenerating the formylglycine residue (step 5). 
an early-onset disease phenotype, the conservative substitution $\mathrm{D} 32 \mathrm{E}$ is associated with late-onset disease, presumably owing to a partly retained $\mathrm{Ca}^{2+}$-binding capability.

4.4.1. Common mutations. Significant regional variations in the frequency of particular mutations have been described in MPS IIIA patients. Thus, R74C occurs in $56 \%$ of disease alleles in Polish patients, $50 \%$ of those in patients from

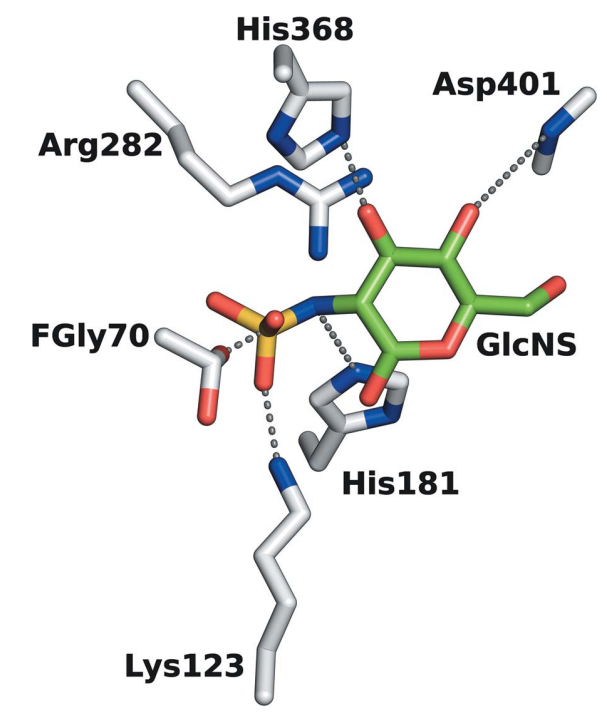

Figure 6

Hypothetical model showing some proposed interactions between the terminal $N$-sulfoglucosamine residue (GlcNS; C atoms in green, other atoms in standard colours) of the substrate with the enzyme in the active site (C atoms in light grey). His181 acts as the acid facilitating desulfation of the substrate. Other residues that help to bind and orient the substrate include the side chains of FGly70, Lys123, Arg282 and His368 and the main-chain amide $\mathrm{N}$ atom of Asp401.
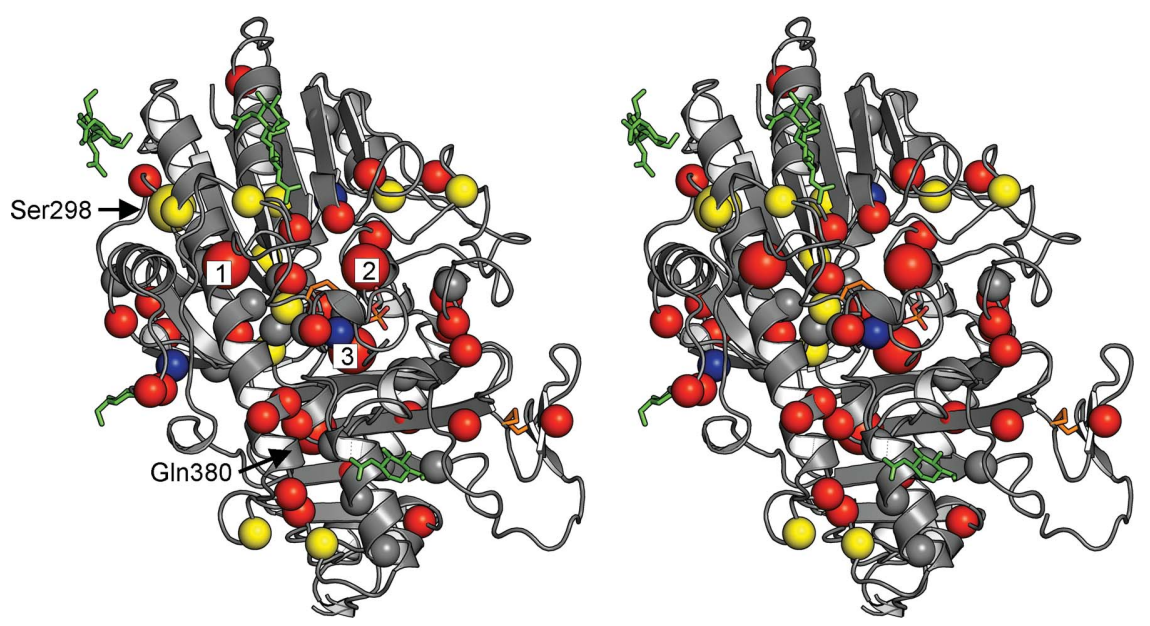

Figure 7

Stereo figure showing missense mutations mapped onto the structure of the SGSH monomer. $\mathrm{C}^{\alpha}$ atoms of residues associated with an early-onset phenotype are shown in red, those associated with an intermediate-onset phenotype in blue and those associated with a late-onset phenotype in yellow. Missense mutations for which the phenotype was not reported are indicated in grey. Most mutations with known phenotype are early-onset mutations. Late-onset mutations appear to map closer to the periphery of the enzyme. Some of the most common mutations are indicated by a larger ball size. These are Ser298, Arg245 (indicated '1'), Arg74 ('2'), Ser66 ('3') and Gln380. The orientation shown is the same as for one of the subunits (on the left) of the dimer in Fig. 2(b); the active site is indicated by FGly70 (stick model; standard colours) and $\mathrm{Ca}^{2+}$ ion (black ball). Glycosylations are shown as green sticks.
Finland and Estonia and $21 \%$ of those in patients from Germany (Bunge et al., 1997). Arg74 is identified in the present structure as a buried active-site residue that forms hydrogen bonds to FGly70 and salt bridges with the $\mathrm{Ca}^{2+}$ binding Asp31 and Asp273. A structural comparison with SGSH homologues with known atomic structures shows that it is strictly conserved in all of them, including $\mathrm{BcPMH}$, which otherwise shows only a loose conservation of five of the ten important active-site residues (Table 2). Mutations affecting it would be predicted to impair enzyme function, likely including its stability, resulting in an early-onset disease phenotype, which has been observed for both mutations that affect this residue ( $\mathrm{R} 74 \mathrm{C}$ and $\mathrm{R} 74 \mathrm{H})$.

S66W is associated with an early-onset disease phenotype. It is the most common mutation observed in Italy, occurring in $33 \%$ of disease alleles (Di Natale et al., 1998). Replacement of the buried Ser66 by the bulky aromatic residue tryptophan is likely to disrupt packing in a five-residue loop immediately preceding a helix $(\alpha 2)$ housing active-site residues, including FGly70.

Another common mutation, $\mathrm{R} 245 \mathrm{H}$, is also associated with an early-onset phenotype and has been described in up to $57.8 \%$ of patients from the Netherlands, $35 \%$ of disease alleles from German patients and $20 \%$ of those from patients in the UK (Beesley et al., 2000; Weber et al., 1997; Bunge et al., 1997). The arginine side chain is not typically buried. However, in SGSH the side chain of Arg245, which lies in the middle of the long helix $\alpha 7$, makes a buried salt bridge with Asp179 and hydrogen bonds to Asp179 and Phe197. A histidine in its place would be too bulky at the base and too short, thus tending to destabilize the local structure and packing. This interpretation is consistent with the lack of enzyme activity that has been reported for this mutation (Perkins et al., 1999).

4.4.2. Mutations and the dimer interface. Active SGSH has been shown to be a dimer (Freeman \& Hopwood, 1986; Paschke \& Kresse, 1979). Ten chains of SGSH monomers found in the two crystal forms in the current study associate to form five homodimers. Residues forming the dimer interface were clearly identified. One of the missense mutations directly affects a residue at the dimer interface, namely V486F. Its replacement by the bulky aromatic phenylalanine would lead to a steric clash, destabilizing the dimer interface. The mutation has been shown to be associated with an early-onset disease phenotype.

Additionally, it has consistently been observed that nonsense mutations in the SGSH gene are associated with an earlyonset disease phenotype (Yogalingam \& Hopwood, 2001). The enzyme structure offers a rational molecular explanation. Many residues involved in dimer formation not only belong to the C-terminal domain 2 
Table 3

Missense point mutations in SGSH and their expected effect based on the atomic structure of SGSH.

Abbreviations: NR, not reported; Interm., intermediate; sc, side chain, $\mathrm{H}$ bond, hydrogen bond; NASA, normalized accessible surface area per atom per residue (as a percentage of the maximal value for any internal residue in SGSH).

\begin{tabular}{|c|c|c|c|c|c|}
\hline Protein & Codon & Phenotype & NASA & Type & Effect of mutation on structure \\
\hline M1V & $1 \mathrm{~A}>\mathrm{G}$ & NR & & Signal peptide & Part of signal peptide \\
\hline L12Q & $35 \mathrm{~T}>\mathrm{A}$ & Late & & Signal peptide & Part of signal peptide \\
\hline A30P & $88 \mathrm{G}>\mathrm{C}$ & NR & 0 & Buried & $\begin{array}{l}\text { Steric clash close to } \mathrm{Ca}^{2+} \text {-binding site; loss of } \mathrm{H} \text { bond to } \\
\text { Thr271 }\end{array}$ \\
\hline D32G & $95 \mathrm{~A}>\mathrm{G}$ & Early & 1 & Metal binding & Disruption of $\mathrm{Ca}^{2+}$ binding \\
\hline D32E & $96 \mathrm{C}>\mathrm{A} / \mathrm{G}$ & Late & 1 & Metal binding & Altered $\mathrm{Ca}^{2+}$ binding \\
\hline G33R & $97 \mathrm{G}>\mathrm{A}$ & NR & 4 & Buried & Introduces bulky sc next to $\mathrm{Ca}^{2+}$-binding Asp32 \\
\hline Y40N & $118 \mathrm{~T}>\mathrm{A}$ & Interm. & 13 & Surface & $\begin{array}{l}\text { Loss of } \mathrm{H} \text { bonding to Leu } 294 \text { and Phe } 60 \text {, and of } \pi \text {-stacking } \\
\text { interactions; next to glycosylation site }\end{array}$ \\
\hline $\mathrm{N} 42 \mathrm{~K}$ & $126 \mathrm{C}>\mathrm{A}$ & Early & 6 & Surface & Loss of $\mathrm{H}$ bonding to Ala44, Ile45 and Tyr240; steric clash \\
\hline A44T & $130 \mathrm{G}>\mathrm{A}$ & Early & 31 & Surface & Steric clash at surface site \\
\hline S66W & $197 \mathrm{C}>\mathrm{G}$ & Early & 2 & Buried & $\begin{array}{l}\text { Introduction of bulky sc in buried position in loop close to } \\
\text { active site }\end{array}$ \\
\hline
\end{tabular}

R74C $220 \mathrm{C}>\mathrm{T} \quad$ Early $\quad 0 \quad$ Buried

Disruption of ion pairs/H bonds with $\mathrm{Ca}^{2+}$-binding Asp31, FGly70 and Asp273; possible interference with disulfidebridge formation Reference

Pollard et al. (2013)

Valstar et al. (2010)

Pollard et al. (2013)

Beesley et al. (2000)

Meyer et al. (2008)

Pollard et al. (2013)

Di Natale et al. (1998)

Lee-Chen et al. (2002)

Di Natale et al. (1998), Esposito et al. (2000)

Blanch et al. (1997), Weber et al. (1997), Di Natale et al. (1998), Montfort et al. (1998), Beesley et al. (2000), Chabás et al. (2001), Piotrowska et al. (2009), Valstar et al. (2010), Muschol et al. (2011), Pollard et al. (2013)

Bunge et al. (1997), Weber et al. (1997), Di Natale et al. (1998), Beesley et al. (2000), Esposito et al. (2000), Emre et al. (2002), Muschol et al. (2004, 2011), Meyer et al. (2008), Piotrowska et al. (2009), Valstar et al. (2010), Pollard et al. (2013)

$\begin{array}{lllcl}\text { R74H } & 221 \mathrm{G}>\mathrm{A} & \text { Early } & 0 & \text { Buried } \\ \text { T79P } & 235 \mathrm{~A}>\mathrm{C} & \text { Early } & 0 & \text { Buried } \\ \text { H84Y } & 250 \mathrm{C}>\mathrm{T} & \text { Early } & 1 & \text { Buried } \\ \text { Q85R } & 254 \mathrm{~A}>\mathrm{G} & \text { Early } & 3 & \text { Buried } \\ \text { M88T } & 263 \mathrm{~T}>\mathrm{C} & \text { NR } & 0 & \text { Buried } \\ \text { G90R } & 268 \mathrm{G}>\mathrm{A} & \text { Early } & 0 & \text { Buried } \\ \text { S106R } & 318 \mathrm{C}>\mathrm{A} & \text { Late } & 0 & \text { Buried } \\ \text { T118P } & 352 \mathrm{~A}>\mathrm{C} & \text { NR } & 0 & \text { Buried } \\ \text { G122R } & 364 \mathrm{G}>\mathrm{A} & \text { Interm. } & 1 & \text { Buried } \\ & & & & \\ \text { P128L } & 383 \mathrm{C}>\mathrm{T} & \text { Late } & 22 & \text { Surface } \\ \text { V131M } & 391 \mathrm{G}>\mathrm{A} & \text { Early } & 1 & \text { Buried } \\ \text { T139M } & 416 \mathrm{C}>\mathrm{T} & \text { Early } & 1 & \text { Buried } \\ \text { L146P } & 437 \mathrm{~T}>\mathrm{C} & \text { Early } & 11 & \text { Surface } \\ \text { R150W } & 448 \mathrm{C}>\mathrm{T} & \text { Early } & 1 & \text { Buried } \\ \text { R150Q } & 449 \mathrm{G}>\mathrm{A} & \text { Early } & 1 & \text { Buried } \\ \text { L163P } & 488 \mathrm{~T}>\mathrm{C} & \text { Early } & 8 & \text { Buried } \\ \text { D179N } & 535 \mathrm{G}>\mathrm{A} & \text { Early } & 1 & \text { Buried } \\ \text { P180L } & 539 \mathrm{C}>\mathrm{T} & \text { Late } & 0 & \text { Buried } \\ \text { R182C } & 544 \mathrm{C}>\mathrm{T} & \text { Interm. } & 4 & \text { Buried } \\ \text { G191R } & 571 \mathrm{G}>\mathrm{A} & \text { Early } & 11 & \text { Surface } \\ \text { F193L } & 579 \mathrm{C}>\mathrm{G} & \text { NR } & 0 & \text { Buried }\end{array}$

Disruption of ion pairs/H bonds with $\mathrm{Ca}^{2+}{ }_{\text {-binding Asp31, }}$ FGly70 and Asp273

Disruption of H bonding to Ala75, Ser76 and Leu81

Bunge et al. (1997), Chabás et al. (2001)

Weber et al. (1997), Beesley et al. (2000), Pollard et al. (2013)

Loss of $\mathrm{H}$ bond to Ser364 and Thr475; steric clash in buried Beesley et al. (2000) position

Steric clash

Destabilizes van der Waals interactions in buried position; steric clash

Gain of bulky sc in buried position; change of $\delta / \psi$ angles

Loss of $\mathrm{H}$ bond to Leu109, Val131; clash possibly accommodated within longer, partially surface-exposed loop

Loss of $\mathrm{H}$ bonds to Asp135; destabilizes $\beta$-sheet

Bulky sc in buried position; Gly $\varphi / \psi$ angles

Montfort et al. (1998), Chabás et al. (2001)

Fiorentino et al. (2006)

Bunge et al. (1997), Piotrowska et al. (2009)

Muschol et al. (2004)

Zhang \& Huiping (2008)

Bunge et al. (1997), Di Natale et al. (1998), Beesley et al. (2000), Valstar et al. (2010), Pollard et al. (2013)

Favourably surface-exposed to minimize steric clash; in loop Di Natale et al. $(1998,2003)$ with FGly-binding His 125 and Lys123

Bulky sc in buried position; destabilizes loop with FGly- Weber et al. (1997) binding residues

Bulky sc in buried position; loss of H bond to Glu141 Weber et al. (1997)

Loss of H bond to Ser144; some clash at surface; destabilizes Di Natale et al. (1998) helix $\alpha 5$; close to glycosylation site (Asn151)

Introduction of bulky aromatic sc; loss of salt bridge with Beesley et al. (2000), Chabás et al. Asp179, H bonding to His181

Loss of ion pair with Asp179, H bonding to His181; next to Bunge et al. (1997), Di Natale et al. glycosylated Asn151

Disruption of hydrophobic interactions, H bond to Val159; clash; destabilizes helix $\alpha 6$

Loss of buried salt bridges with Arg150, Arg245

Some steric clash next to active site-residues Asp31 and His181

Loss of ion pair with Asp235, H bond to Pro277 close to active Di Natale et al. (1998), Valstar et al. site; possible interference with disulfide-bridge formation

Surface-exposed but steric clash with scs of Glu195 and Lys196; Gly $\varphi / \psi$ angles

Disrupts $\pi$-stacking next to active-site loop (His181) (2001)

(1998), Chabás et al. (2001), Valsta et al. (2010), Montfort et al. (1998)

Muschol et al. (2004)

Di Natale et al. (1998), Esposito et al. (2000)

Valstar et al. (2010) (2010)

Muschol et al. (2004), Valstar et al. (2010)

Bunge et al. (1997), Yogalingam \& Hopwood (2001) 
Table 3 (continued)

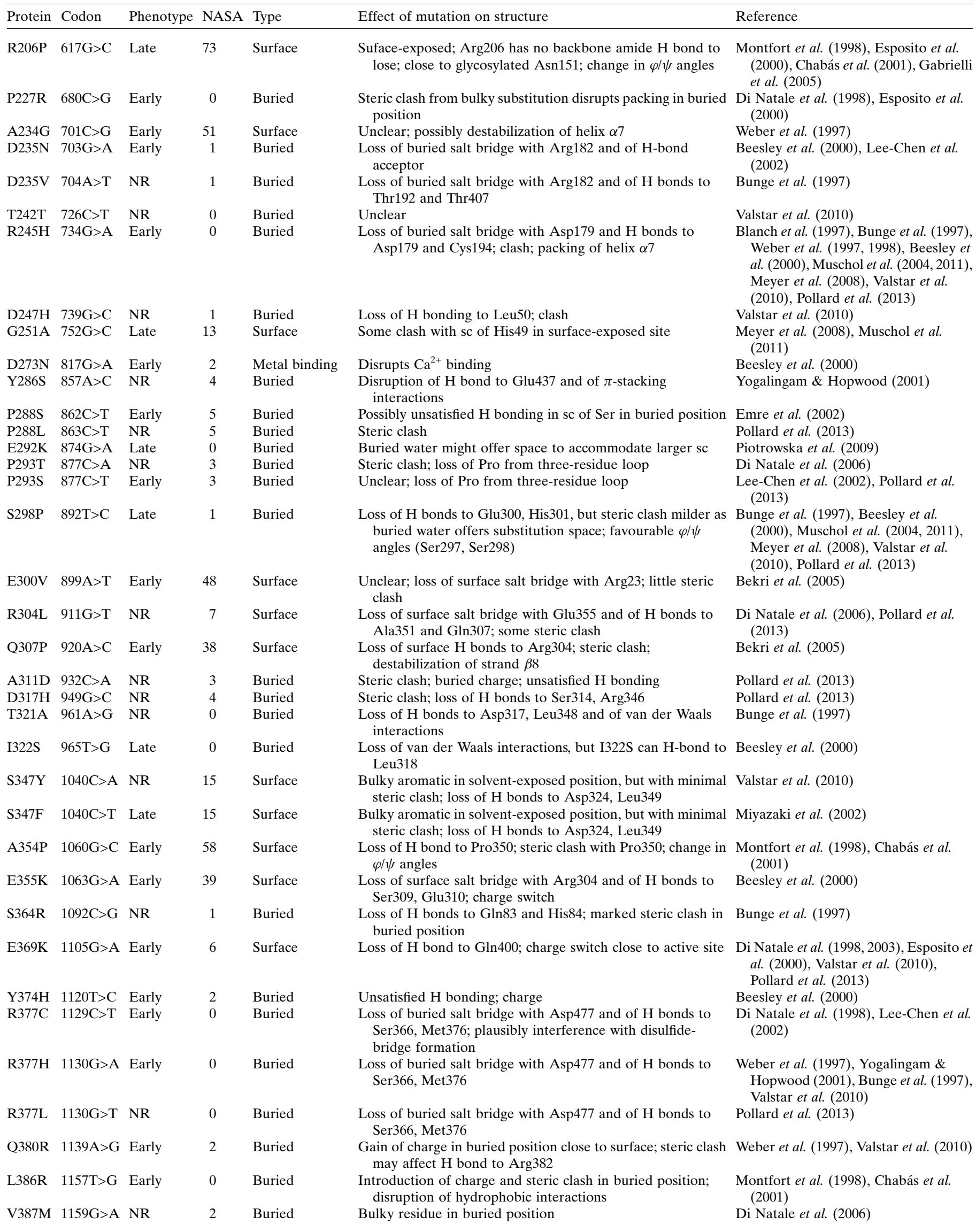


Table 3 (continued)

\begin{tabular}{|c|c|c|c|c|c|c|}
\hline Protein & Codon & Phenotype & NASA & Type & Effect of mutation on structure & Reference \\
\hline N389S & $1166 \mathrm{~A}>\mathrm{G}$ & NR & 0 & Buried & Loss of buried $\mathrm{H}$ bonds to Ala434, Glu437 & Pollard et al. (2013) \\
\hline N389K & $1167 \mathrm{C}>\mathrm{A}$ & NR & 0 & Buried & Loss of buried H bonds to Ala434, Glu437; steric clash & Bunge et al. (1997), Valstar et al. (2010) \\
\hline L411R & $1232 \mathrm{~T}>\mathrm{G}$ & NR & 1 & Buried & $\begin{array}{l}\text { Introduction of charge in buried position; steric clash; } \\
\text { disruption of hydrophobic interactions }\end{array}$ & Valstar et al. (2010) \\
\hline T415P & $1243 \mathrm{~A}>\mathrm{C}$ & NR & 34 & Surface & $\begin{array}{l}\text { Loss of } \mathrm{H} \text { bond to Leu } 411 \text {; steric clash with Leu411; kink in } \\
\text { helix } \alpha 11 \text { close to glycosylation site }\end{array}$ & Pollard et al. (2013) \\
\hline T421R & $1262 \mathrm{C}>\mathrm{G}$ & Late & 16 & Surface & $\begin{array}{l}\text { Loss of } \mathrm{H} \text { bond to Trp423; solvent exposure accommodates } \\
\text { bulky sc }\end{array}$ & Valstar et al. (2010) \\
\hline R433W & $1297 \mathrm{C}>\mathrm{T}$ & Early & 6 & Buried & $\begin{array}{l}\text { Loss of buried } \mathrm{H} \text { bonds to Asn284, Tyr430 and of charge; } \\
\text { steric clash }\end{array}$ & $\begin{array}{l}\text { Beesley et al. (2000), Yogalingam \& } \\
\text { Hopwood (2001), Chabás et al. } \\
\text { (2001), Muschol et al. (2004), Pollard } \\
\text { et al. (2013) }\end{array}$ \\
\hline R433Q & $1298 \mathrm{G}>\mathrm{A}$ & Early & 6 & Buried & $\begin{array}{l}\text { Loss of buried } \mathrm{H} \text { bonds to Asn284, Tyr } 430 \text { and of charge; } \\
\text { destabilizes packing }\end{array}$ & $\begin{array}{l}\text { Chabás et al. (2001), Di Natale et al. } \\
\text { (2003), Valstar et al. (2010) }\end{array}$ \\
\hline D444G & $1331 \mathrm{~A}>\mathrm{G}$ & Late & 13 & Surface & Loss of surface $\mathrm{H}$ bonds to $\mathrm{Thr} 448, \mathrm{G} \ln 449$ & Miyazaki et al. (2002) \\
\hline E447K & $1339 \mathrm{G}>\mathrm{A}$ & Early & 8 & Surface & Switch of charge in partly buried location & Blanch et al. (1997), Chabás et al. (2001) \\
\hline Q472H & $1416 \mathrm{G}>\mathrm{C}$ & NR & 6 & Surface & Loss of $\mathrm{H}$ bond to Asp477 & Pollard et al. (2013) \\
\hline V486F & $1456 \mathrm{G}>\mathrm{T}$ & Late & 37 & Dimer interface & Disruption of dimer interface & Beesley et al. (2000) \\
\hline
\end{tabular}

but also lie in close proximity to the C-terminus, including Leu487, Glu488, Pro497, Leu498 and the third-last residue Asn500. Nonsense mutations where even a relatively minor part of domain 2 is missing may be predicted to be destabilizing to the dimer interface. Since part of the access to the active-site pocket is formed by the second subunit in the dimer, this would be likely to affect the binding of heparin and heparan sulfatate and thus disrupt enzyme function.

\subsection{Prospects}

The wild-type structure provides a rational basis for understanding the effects of many mutations. It may be useful in predicting the phenotype of mutations of unreported phenotype or as yet unknown genotype. Although it is possible to envisage significant divergence from the wild-type structure in some mutations, the low structural flexibility of SGSH suggests a promising effect of molecular chaperones in the cases of many missense mutations (Boyd et al., 2013). Molecular chaperones that bind to the active site and reconstitute its structural architecture might be promising at first hand. In addition, small molecules with allosteric or stabilizing effect may be beneficial in the cases of mutations located more distantly from the active site or at the SGSH surface. In vitro studies that test for the rescue of SGSH activity may be the initial step to evaluate structure-based chaperones before clinical trials can further prove the effectiveness of these small molecules. Additionally, the SGSH structure will be very useful for the engineering of SGSH variants or fusion proteins with beneficial biological features that increase its therapeutic effectiveness in enzyme-replacement therapy and other treatment modalities (Sly \& Vogler, 2013; Sorrentino et al., 2013).

\section{Conclusions}

The structure of SGSH determined to 2.0 Å resolution clearly extends our understanding of the molecular pathology underlying MPS IIIA and thus lays the groundwork for the development of the structure-based rational design of general and mutation-specific therapeutic tools such as molecular chaperones. In addition, the crystal structure provides fundamental atomic-level knowledge for protein modifications, with the aim of facilitating the transport of SGSH across the blood-brain barrier. Chemically synthesized protein modifications or genetically engineered fusion proteins can enter the brain via endogenous receptor-mediated endocytosis of the attached ligand (Pardridge, 2007). Since the brain is the organ most severely affected in MPS IIIA, cerebral delivery is absolutely crucial for successful treatment of this devastating disorder.

We thank Tim Grüne for helpful discussion of data processing, and Birger Dittrich and the SLS beamline PXII staff for their kind help and support in data collection. This work was funded by the DFG. Partial support from DFG grant No. SH 14/5-1 is gratefully acknowledged (NSS). IU is grateful to the Spanish MEC and Generalitat de Catalunya for financial support (grants BFU2012-35367, IDC-20101173 and 2009SGR-1036).

\section{References}

Baehner, F., Schmiedeskamp, C., Krummenauer, F., Miebach, E., Bajbouj, M., Whybra, C., Kohlschütter, A., Kampmann, C. \& Beck, M. (2005). J. Inherit. Metab. Dis. 28, 1011-1017.

Ballabio, A. \& Gieselmann, V. (2009). Biochim. Biophys. Acta, 1793, 684-696.

Beesley, C. E., Young, E. P., Vellodi, A. \& Winchester, B. G. (2000). J. Med. Genet. 37, 704-707.

Bekri, S., Armana, G., De Ricaud, D., Osenda, M., Maire, I., Van Obberghen, E. \& Froissart, R. (2005). J. Inherit. Metab. Dis. 28, 601-602.

Bielicki, J., Fuller, M., Guo, X.-H., Morris, C. P., Hopewood, J. J. \& Anson, D. S. (1995). Biochem. J. 311, 333-339.

Blanch, L., Weber, B., Guo, X.-H., Scott, H. S. \& Hopwood, J. J. (1997). Hum. Mol. Genet. 6, 787-791.

Boltes, I., Czapinska, H., Kahnert, A., von Bülow, R., Dierks, T., Schmidt, B., von Figura, K., Kertesz, M. A. \& Usón, I. (2001). Structure, 9, 483-491.

Bond, C. S., Clements, P. R., Ashby, S. J., Collyer, C. A., Harrop, S. J., Hopwood, J. J. \& Guss, J. M. (1997). Structure, 5, 277-289. 
Boyd, R. E., Lee, G., Rybczynski, P., Benjamin, E. R., Khanna, R., Wustman, B. A. \& Valenzano, K. J. (2013). J. Med. Chem. 56, 27052725.

Brünger, A. T. (1992). Nature (London), 355, 472-475.

Bülow, R. von, Schmidt, B., Dierks, T., von Figura, K. \& Usón, I. (2001). J. Mol. Biol. 305, 269-277.

Bunge, S., Ince, H., Steglich, C., Kleijer, W. J., Beck, M., Zaremba, J., van Diggelen, O. P., Weber, B., Hopwood, J. J. \& Gal, A. (1997). Hum. Mutat. 10, 479-485.

Chabás, A., Montfort, M., Martínez-Campos, M., Díaz, A., Coll, M. J., Grinberg, D. \& Vilageliu, L. (2001). Am. J. Med. Genet. 100, 223-228.

Chruszcz, M., Laidler, P., Monkiewicz, M., Ortlund, E., Lebioda, L. \& Lewinski, K. (2003). J. Inorg. Biochem. 96, 386-392.

Clarke, L. A. (2008). Expert Rev. Mol. Med. 10, e1.

Cowtan, K. (1994). Jnt CCP4/ESF-EACBM Newsl. Protein Crystallogr. 31, 34-38.

Cowtan, K. (2006). Acta Cryst. D62, 1002-1011.

Daniele, A. \& Di Natale, P. (2001). FEBS Lett. 505, 445-448.

Dierks, T., Dickmanns, A., Preusser-Kunze, A., Schmidt, B., Mariappan, M., von Figura, K., Ficner, R. \& Rudolph, M. G. (2005). Cell, 121, 541-552.

Dierks, T., Lecca, M. R., Schlotterhose, P., Schmidt, B. \& von Figura, K. (1999). EMBO J. 18, 2084-2091.

Di Natale, P., Balzano, N., Esposito, S. \& Villani, G. R. (1998). Hum. Mutat. 11, 313-320.

Di Natale, P., Pontarelli, G., Villani, G. R. D. \& Di Domenico, C. (2006). Hum. Genet. 119, 679.

Di Natale, P., Vanacore, B., Daniele, A. \& Esposito, S. (2001). Biochem. Biophys. Res. Commun. 280, 1251-1257.

Di Natale, P., Villani, G. R., Di Domenico, C., Daniele, A., Dionisi Vici, C. \& Bartuli, A. (2003). Clin. Genet. 63, 314-318.

Emre, S., Terzioglu, M., Tokatli, A., Coskun, T., Ozalp, I., Weber, B. \& Hopwood, J. J. (2002). Hum. Mutat. 19, 184-185.

Emsley, P., Lohkamp, B., Scott, W. G. \& Cowtan, K. (2010). Acta Cryst. D66, 486-501.

Esposito, S., Balzano, N., Daniele, A., Villani, G. R. D., Perkins, K., Weber, B., Hopwood, J. J. \& Di Natale, P. (2000). Biochim. Biophys. Acta, 1501, 1-11.

Fiorentino, F., Biricik, A., Nuccitelli, A., De Palma, R., Kahraman, S., Iacobelli, M., Trengia, V., Caserta, D., Bonu, M. A., Borini, A. \& Baldi, M. (2006). Hum. Reprod. 21, 670-684.

Freeman, C. \& Hopwood, J. J. (1986). Biochem. J. 234, 83-92.

Fromm, J. R., Hileman, R. E., Caldwell, E. E., Weiler, J. M. \& Linhardt, R. J. (1995). Arch. Biochem. Biophys. 323, 279-287.

Gabrielli, O., Coppa, G. V., Bruni, S., Villani, G. R., Pontarelli, G. \& Di Natale, P. (2005). Am. J. Med. Genet. A, 133, 85-89.

Goujon, M., McWilliam, H., Li, W., Valentin, F., Squizzato, S., Paern, J. \& Lopez, R. (2010). Nucleic Acids Res. 38, W695-W699.

Grune, T. (2008). J. Appl. Cryst. 41, 217-218.

Héron, B. et al. (2011). Am. J. Med. Genet. A, 155, 58-68.

Hernandez-Guzman, F. G., Higashiyama, T., Pangborn, W., Osawa, Y. \& Ghosh, D. (2003). J. Biol. Chem. 278, 22989-22997.

Kabsch, W. (1976). Acta Cryst. A32, 922-923.

Kabsch, W. (2010). Acta Cryst. D66, 125-132.

Kabsch, W. \& Sander, C. (1983). Biopolymers, 22, 2577-2637.

Karplus, P. A. \& Diederichs, K. (2012). Science, 336, 1030-1033.

Karpova, E. A., Voznyi, Y. V., Keulemans, J. L., Hoogeveen, A. T., Winchester, B., Tsvetkova, I. V. \& van Diggelen, O. P. (1996). J. Inherit. Metab. Dis. 19, 278-285.

Krissinel, E. \& Henrick, K. (2007). J. Mol. Biol. 372, 774-797.

Krivov, G. G., Shapovalov, M. V. \& Dunbrack, R. L. Jr (2009). Proteins, 77, 778-795.

Lee, G. D. \& Van Etten, R. L. (1975). Arch. Biochem. Biophys. 166, 280-294.

Lee-Chen, G. J., Lin, S. P., Ko, M. H., Chuang, C. K., Chen, C. P., Lee, H. H., Cheng, S. C., Shen, C. H., Tseng, K. L. \& Li, C. L. (2002). Clin. Genet. 61, 192-197.
Loo, B. van, Jonas, S., Babtie, A. C., Benjdia, A., Berteau, O., Hyvönen, M. \& Hollfelder, F. (2010). Proc. Natl Acad. Sci. USA, 107, 2740-2745.

Lovell, S. C., Davis, I. W., Arendall, W. B. III, de Bakker, P. I., Word, J. M., Prisant, M. G., Richardson, J. S. \& Richardson, D. C. (2003). Proteins, 15, 437-450.

Lukatela, G., Krauss, N., Theis, K., Selmer, T., Gieselmann, V., von Figura, K. \& Saenger, W. (1998). Biochemistry, 37, 3654-3664.

Madsen, D., Johansson, P., Johansson, N., Arent, S., Harris, M. R. \& Kleywegt, G. J. (2005). Indonesia: An Integrated Workbench for Sequence and Structure Alignment and Analysis. Uppsala University, Uppsala, Sweden.

Marino, T., Russo, N. \& Toscano, M. (2013). Chemistry, 19, 2185-2192.

McCoy, A. J., Grosse-Kunstleve, R. W., Adams, P. D., Winn, M. D., Storoni, L. C. \& Read, R. J. (2007). J. Appl. Cryst. 40, 658-674.

Meyer, A., Kossow, K., Gal, A., Steglich, C., Muhlhausen, C., Ullrich, K., Braulke, T. \& Muschol, N. (2008). Hum. Mutat. 29, 770.

Miyazaki, T., Masuda, N., Waragai, M., Motoyoshi, Y., Kurokawa, K. \& Yuasa, T. (2002). J. Neurol. Neurosurg. Psychiatry, 73, 777-778.

Montfort, M., Vilageliu, L., Garcia-Giralt, N., Guidi, S., Coll, M. J., Chabás, A. \& Grinberg, D. (1998). Hum. Mutat. 12, 274-279.

Müller, P., Köpke, S. \& Sheldrick, G. M. (2003). Acta Cryst. D59, 32-37.

Mura, C., McCrimmon, C. M., Vertrees, J. \& Sawaya, M. R. (2010). PLoS Comput. Biol. 6, e1000918.

Murshudov, G. N., Skubák, P., Lebedev, A. A., Pannu, N. S., Steiner, R. A., Nicholls, R. A., Winn, M. D., Long, F. \& Vagin, A. A. (2011). Acta Cryst. D67, 355-367.

Murshudov, G. N., Vagin, A. A. \& Dodson, E. J. (1997). Acta Cryst. D53, 240-255.

Muschol, N., Pohl, S., Meyer, A., Gal, A., Ullrich, K. \& Braulke, T. (2011). Am. J. Med. Genet. A, 155, 1634-1639.

Muschol, N., Storch, S., Ballhausen, D., Beesley, C., Westermann, J. C., Gal, A., Ullrich, K., Hopwood, J. J., Winchester, B. \& Braulke, T. (2004). Hum. Mutat. 23, 559-566.

Myette, J. R., Soundararajan, V., Behr, J., Shriver, Z., Raman, R. \& Sasisekharan, R. (2009). J. Biol. Chem. 284, 35189-35200.

Nardini, M. \& Dijkstra, B. W. (1999). Curr. Opin. Struct. Biol. 9, 732-737.

Pardridge, W. M. (2007). Pharm. Res. 24, 1733-1744.

Paschke, E. \& Kresse, H. (1979). Biochem. J. 181, 677-684.

Pei, J., Kim, B.-H. \& Grishin, N. V. (2008). Nucleic Acids Res. 36, 2295-2300.

Perkins, K. J., Byers, S., Yogalingam, G., Weber, B. \& Hopwood, J. J. (1999). J. Biol. Chem. 274, 37193-37199.

Piotrowska, E., Jakóbkiewicz-Banecka, J., Tylki-Szymańska, A., Czartoryska, B., Wegrzyn, A. \& Wegrzyn, G. (2009). Acta Paediatr. 98, 743-749.

Pollard, L. M., Jones, J. R. \& Wood, T. C. (2013). J. Inherit. Metab. Dis. 36, 179-187.

Ramakrishnan, C. \& Ramachandran, G. N. (1965). Biophys. J. 5, 909-933.

Rivera-Colón, Y., Schutsky, E. K., Kita, A. Z. \& Garman, S. C. (2012). J. Mol. Biol. 423, 736-751.

Rodríguez, D. D., Grosse, C., Himmel, S., González, C., de Ilarduya, I. M., Becker, S., Sheldrick, G. M. \& Usón, I. (2009). Nature Methods, 6, 651-653.

Sheldrick, G. M. (2012). XPREP. Bruker AXS Inc., Madison, Wisconsin, USA.

Sly, W. S. \& Vogler, C. (2013). EMBO Mol. Med. 5, 655-657.

Sorrentino, N. C., D'Orsi, L., Sambri, I., Nusco, E., Monaco, C., Spampanato, C., Polishchuk, E., Saccone, P., De Leonibus, E., Ballabio, A. \& Fraldi, A. (2013). EMBO Mol. Med. 5, 675-690.

Steinfeld, R., Steinke, H. B., Isbrandt, D., Kohlschütter, A. \& Gärtner, J. (2004). Hum. Mol. Genet. 13, 2483-2491.

Stenlund, P., Lindberg, M. J. \& Tibell, L. A. (2002). Biochemistry, 41, 3168-3175.

Trott, O. \& Olson, A. J. (2010). J. Comput. Chem. 31, 455-461. 
Turnbull, J. E., Miller, R. L., Ahmed, Y., Puvirajesinghe, T. M. \& Guimond, S. E. (2010). Methods Enzymol. 480, 65-85.

Valstar, M. J., Neijs, S., Bruggenwirth, H. T., Olmer, R., Ruijter, G. J., Wevers, R. A., van Diggelen, O. P., Poorthuis, B. J., Halley, D. J. \& Wijburg, F. A. (2010). Ann. Neurol. 68, 876-887.

Weber, B., Guo, X.-H., Wraith, J. E., Cooper, A., Kleijer, W. J., Bunge, S. \& Hopwood, J. J. (1997). Hum. Mol. Genet. 6, 1573-1579.
Weber, B., van de Kamp, J. J., Kleijer, W. J., Guo, X.-H., Blanch, L., van Diggelen, O. P., Wevers, R., Poorthuis, B. J. \& Hopwood, J. J. (1998). J. Inherit. Metab. Dis. 21, 416-422.

Winn, M. D. et al. (2011). Acta Cryst. D67, 235-242.

Yogalingam, G. \& Hopwood, J. J. (2001). Hum. Mutat. 18, 264281.

Zhang, W. \& Huiping, S. (2008). Hum. Genet. 124, 323. 